
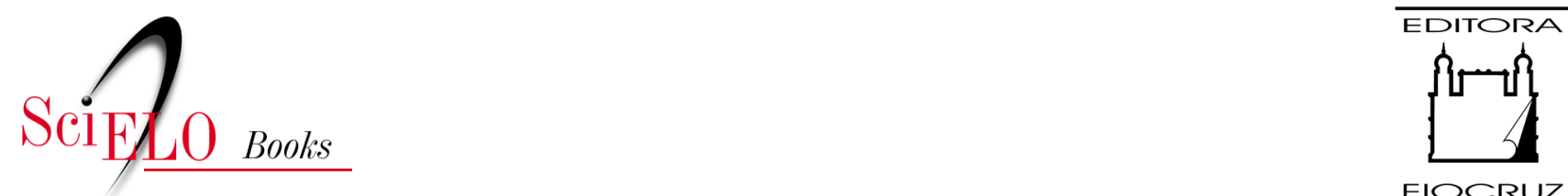

FIOCRUZ

\title{
2. Dinâmica demográfica e distribuição espacial da população o acesso aos serviços de saúde
}

\author{
Antônio Tadeu Ribeiro de Oliveira \\ Maria Monica Vieira Caetano O’Neill
}

\section{SciELO Books / SciELO Livros / SciELO Libros}

OLIVEIRA, A.T.R., and O’NEILL, M.M.V.C. Dinâmica demográfica e distribuição espacial da população: o acesso aos serviços de saúde. In: GADELHA, P., NORONHA, J.C., DAIN, S., and PEREIRA, T.R., eds. Brasil Saúde Amanhã: população, economia e gestão [online]. Rio de Janeiro: Editora FIOCRUZ, 2016, pp. 39-74. ISBN: 978-65-5708-093-1.

https://doi.org/10.7476/9786557080931.0004.

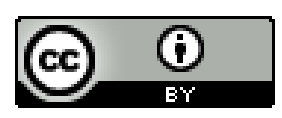

All the contents of this work, except where otherwise noted, is licensed under a Creative Commons Attribution 4.0 International license.

Todo o conteúdo deste trabalho, exceto quando houver ressalva, é publicado sob a licença Creative Commons Atribição 4.0.

Todo el contenido de esta obra, excepto donde se indique lo contrario, está bajo licencia de la licencia $\underline{\text { Creative }}$ Commons Reconocimento 4.0. 


\title{
DINÂMICA DEMOGRÁFICA E DISTRIBUIÇÃO ESPACIAL DA POPULAÇÃO: O ACESSO AOS SERVIÇOS DE SAÚDE
}

\author{
Antônio Tadeu Ribeiro de Oliveira \\ Maria Monica Vieira Caetano O’Neill
}

O Brasil vem experimentando transformações importantes em seus componentes demográficos: o processo veloz e continuado na redução dos níveis da fecundidade, que vem impactando na diminuição das taxas de natalidade; o envelhecimento populacional, reflexo da própria redução da fecundidade, do aumento relativo e absoluto da população idosa e da esperança de vida ao nascer (E0); e as mudanças na direção dos fluxos migratórios, que cada vez mais se destinam às cidades médias, com redução na participação relativa nas grandes metrópoles. Essas transformações, combinadas ao comportamento da distribuição espacial da população, fruto dos novos arranjos locacionais das atividades econômicas pelo território nacional, vêm imprimindo nos últimos vinte anos uma nova dinâmica demográfica ao país, que deve ser mais bem compreendida, inclusive no que tange aos seus impactos na transição epidemiológica e no acesso aos equipamentos e serviços de saúde.

Em relação aos cenários demográficos traçados em estudo anterior (Oliveira \& Oneill, 2013), as recentes projeções divulgadas pelo Instituto Brasileiro de Geografia e Estatística (IBGE), muito embora ratifiquem o diagnóstico e as tendências futuras apontadas, revisaram alguns indicadores, como já antecipávamos, fundamentalmente a taxa de fecundidade total (TFT) e a taxa de mortalidade infantil (TMI). Essa revisão implicou um ritmo mais lento no declínio da fecundidade, retardando em alguns anos a diminuição no tamanho da população brasileira.

Uma vez tendo avançado no diagnóstico e na construção de cenários para a transição demográfica brasileira para o nível macro, no horizonte de 2030, a questão que se coloca é a investigação dos efeitos dessas transformações na escala subnacional. Resguardados os diferenciais regionais, a tendência de redução nos níveis da fecundidade e da mortalidade aponta para a convergência desses indicadores em todo o espaço nacional, implicando a redução do número de crianças e o aumento da longevidade. Nesse sentido, o comportamento dos movimentos migratórios internos ditará, na maioria dos casos, não só o ritmo de crescimento dos espaços sub-regionais e, consequentemente, dos respectivos municípios, como também a estrutura por sexo e idade dessas populações, sem esquecer os movimentos pendulares que impactarão a demanda por acesso ao mercado de trabalho e serviços, em especial, os de saúde.

Dessa forma, espera-se que uma política de saúde, com dimensões abrangentes do ponto de vista econômico, social, político e territorial, seja tanto eficiente e duradoura, quanto inclusiva, no sentido 
de assistir e incorporar os mais variados segmentos populacionais nas diferentes regiões do país. No caso da saúde, o planejamento sob a ótica territorial permite direcionar a localização de investimentos e serviços (públicos e privados), assim como possibilitar maior acesso da população aos serviços.

A análise preliminar, relacionada ao cenário demográfico, sua dinâmica e distribuição espacial, aliada ao exame dos fluxos de internações para procedimentos de alta e média complexidade, preparados no contexto da iniciativa Brasil Saúde Amanhã (Oliveira \& O’Neill, 2013), permitiu afirmar que a oferta dos serviços de atendimento à saúde estaria repetindo o padrão de assimetrias mais geral, deixando à margem do acesso à saúde parcela significativa da população. A saúde apresenta uma configuração espacial desigual, beneficiando, de forma diferenciada, grupos sociais e lugares.

A superação das distorções que ocorrem no âmbito da distribuição e acesso a serviços de saúde aflora como uma questão crucial que pressupõe a ação do Estado, por meio da identificação e classificação de um conjunto de polos urbanos e suas regiões imediatas de articulação urbana a serem incentivados e destinados a ampliar e conformar redes de atendimento à saúde.

Para tratar dessas questões, o capítulo está estruturado de forma a inicialmente apresentar os indicadores demográficos associados ao comportamento da fecundidade (TFT); os relacionados à estrutura etária da população, como a razão de dependência total (RDT), de idosos (RDI) e o índice de envelhecimento (IE); os que dizem respeito à mortalidade (E0 e TMI); e a mobilidade espacial interestadual da população, vista a partir dos saldos migratórios, sempre destacando e enfatizando os diferenciais regionais.

Em seguida, para definir o quadro territorial dos centros de saúde e suas regiões de influência imediata, foi utilizada a Divisão Urbano-Regional (IBGE, 2013a), mais especificamente as regiões imediatas de articulação urbana (Figura 1), delimitadas a com base no estudo Regiões de Influência das Cidades - 2007 (IBGE, 2008). As regiões imediatas possuem, de maneira geral, tamanho populacional e áreas menores que as de nível intermediário, e suas ligações refletem a acessibilidade e a capacidade de atender demandas de amplitude mais restritas.

Utilizar a Divisão Urbano-Regional como referencial espacial para analisar e atuar no território significa privilegiar os núcleos da rede urbana e suas regiões de articulação, obtidos com base na combinação de dois processos: urbanização e integração do mercado nacional. As interações espaciais ocorrem conformando redes com alcance e intensidade variados e expressam a inserção diferenciada de cada centro na estrutura produtiva do país. A rede urbana, nesse contexto, exerce papel fundamental, contribuindo como o principal lócus na decisão e ação direta do governo no cotidiano das pessoas.

Na caracterização dos polos de saúde, foram utilizados critérios de saúde e populacionais que forneceram os perfis dos polos e de suas regiões de articulação. As unidades territoriais utilizadas são os municípios adotados pela Divisão Urbano-Regional (IBGE, 2013a), com a identificação dos polos e as vinculações com as regiões de articulação a que pertencem. Os critérios populacionais utilizados caracterizam os lugares segundo o tamanho e a dinâmica de seu crescimento até 2033. 
Figura 1 - Divisão Urbano-Regional - regiões imediatas de articulação

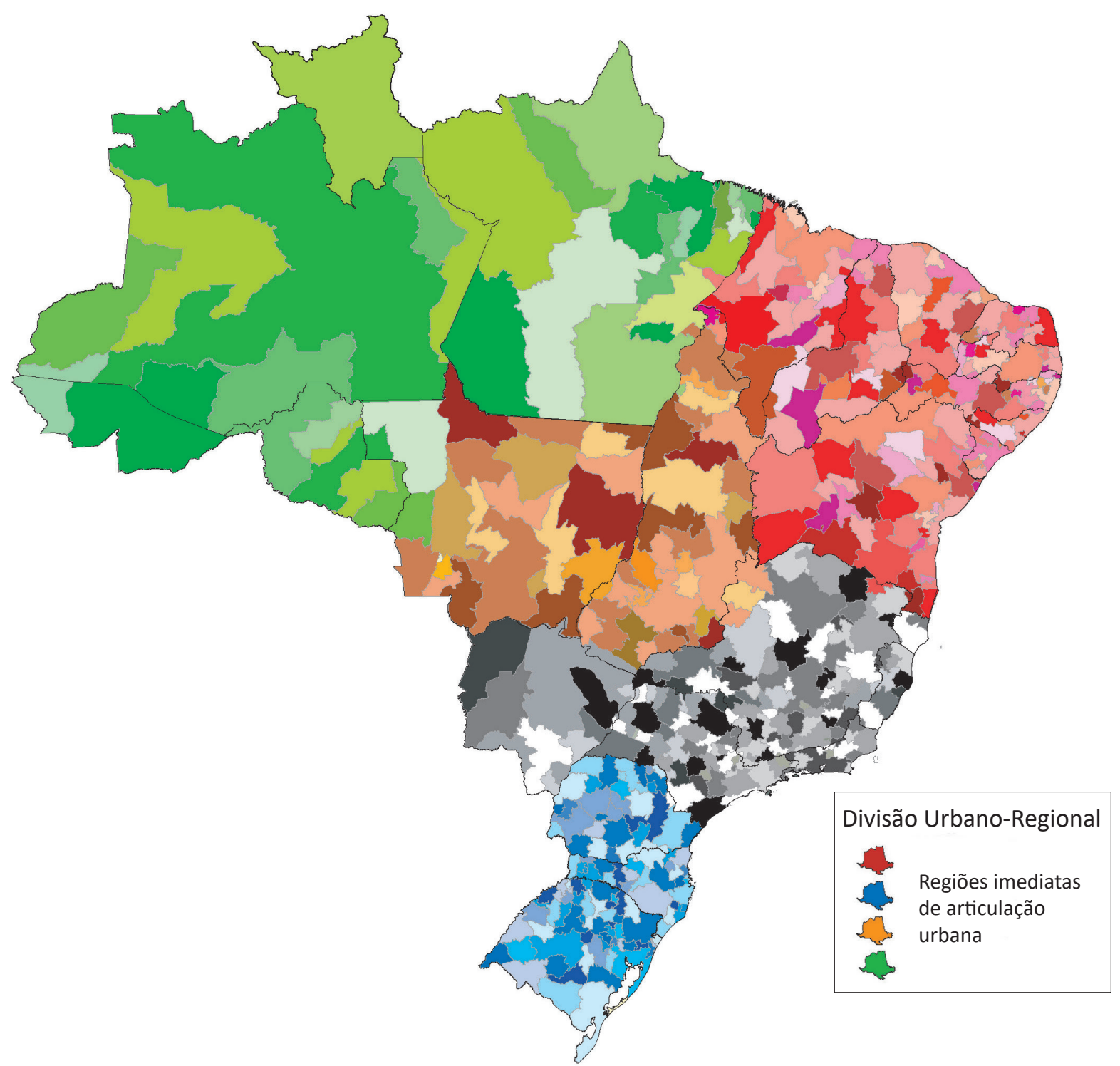

Fonte: elaboração dos autores com base em dados do IBGE - Coordenação de Geografia/Diretoria de Geociências.

O estudo Regiões de Influência das Cidades - 2007 (IBGE, 2008) foi a fonte analítica para definir os níveis de centralidade em saúde. Esses níveis expressam a capacidade que determinados serviços de saúde têm de dotar os centros urbanos com graus de atratividade diferenciados em suas áreas de atuação, ou ainda, o papel que os centros têm como distribuidores de bens e serviços de saúde para a população. Os resultados qualificam os centros que se posicionam entre os menos especializados até os mais especializados, com menor ou maior complexidade em serviços e capacidade de atendimento hospitalar, consequentemente, com níveis de centralidade menores e maiores. 


\section{Os Indicadores Demográficos e os Diferenciais Regionais}

Como mencionado anteriormente, o cenário futuro para o comportamento da dinâmica demográfica brasileira se alterou ligeiramente com a divulgação recente das projeções populacionais (IBGE, 2013b). Com essa mudança, no ano de 2030, o volume populacional atingirá a cifra de 223,1 milhões (7 milhões de habitantes a mais, resultado obtido, sobretudo, em virtude do declínio mais lento das taxas de fecundidade das mulheres brasileiras). Na revisão anterior, realizada em 2008, estimava-se que a TFT partiria de um patamar de 1,76 filho por mulher e chegaria a 1,5 em 2030. Com a atual revisão, o nível de partida foi de 1,87 filho por mulher, alcançando 1,51 em 2030. Como podemos observar, tanto em uma quanto na outra projeção, o ponto de partida para a hipótese do nível da fecundidade estava num patamar abaixo do de reposição (2,1 filhos por mulher). Mais à frente, quando formos tratar desses indicadores desagregados por unidade da federação (UF), veremos que a tendência é de convergência para níveis baixos das taxas de fecundidade.

Embora com indicadores finais muito próximos, a menor velocidade na redução dos níveis da fecundidade fez com que indicadores, como as razões de dependência, índice de envelhecimento populacional e o momento de redução no volume populacional, também se alterassem, mesmo que ligeiramente, em relação à projeção anterior.

Por exemplo, a RDT, ${ }^{1}$ que anteriormente voltaria a aumentar por volta de 2022 , quando teríamos 51,2 pessoas em idade não ativa para cada 100 em idade ativa (15 a 59 anos), agora inverterá sua tendência de declínio em 2020, alcançando a cifra de 53,2\%, o que significará uma pressão ligeiramente maior sobre aqueles que, hipoteticamente, estarão no mercado de trabalho. Ao decompormos a razão de dependência para jovens (RDJ) e idosos (RDI), observaremos que essa relação irá se alterando em favor do segmento com maior idade. Enquanto nos dias de hoje, essa relação é de cerca de 37,2 jovens e 16,9 idosos para cada 100 pessoas em idade ativa, em 2030 passaremos a ter aproximadamente 27,6 jovens e 29,2 idosos.

Esse processo de envelhecimento populacional fica ainda mais evidenciado quando verificamos o IE, que é a razão entre a população idosa e a jovem. Se na projeção anterior estimava-se 39 idosos para cada 100 jovens, em 2010, projetando-se para 2030, essa razão seria de 110,1 idosos. Com as novas projeções esses valores passaram a 39,3, em 2010, chegando em 2030 com um IE de 105,8\%. Aqui estamos falando de 41,5 milhões de pessoas com 60 anos ou mais de idade, mais do que o dobro observado em 2010 (19,6 milhões). Em comparação com a projeção anterior, embora tenhamos um IE menor, o volume de população idosa esperada é maior nesse novo cenário.

A população em idade ativa, por sua vez, continuará aumentando em volume até atingir seu ápice em 2033, quando teríamos cerca de 142,1 milhões de pessoas entre 15 e 59 anos de idade. A combinação desse fator, com a já anunciada maior participação da RDI e do IE, ocasionará sérios impactos na produtividade dessa força de trabalho, sem contar a sobrecarga sobre o sistema de saúde.

\footnotetext{
${ }^{1}$ Para guardar uma relação mais estreita com os indicadores utilizados na área da saúde, consideraram-se, no cálculo das razões de dependência e IE, os seguintes segmentos etários: idosos - 60 anos ou mais, jovens -0 a 14 anos, e idade ativa -15 a 59 anos.
} 
Nesse novo ritmo do processo de envelhecimento populacional, que refletirá a associação entre a diminuição da taxa bruta de natalidade, em decorrência da redução dos níveis de fecundidade, e o aumento das taxas brutas de mortalidade, em face do envelhecimento, chegaremos a um ponto no qual o crecimento vegetativo será negativo, o que deverá ocorrer no inicío dos anos 2040, quando atingiremos o máximo de 228,3 milhões de habitantes. Os Gráficos 1 e 2 sintetizam tais processos.

Gráfico 1 - Estimativas das taxas brutas de natalidade e mortalidade. Brasil - 2010 - 2060

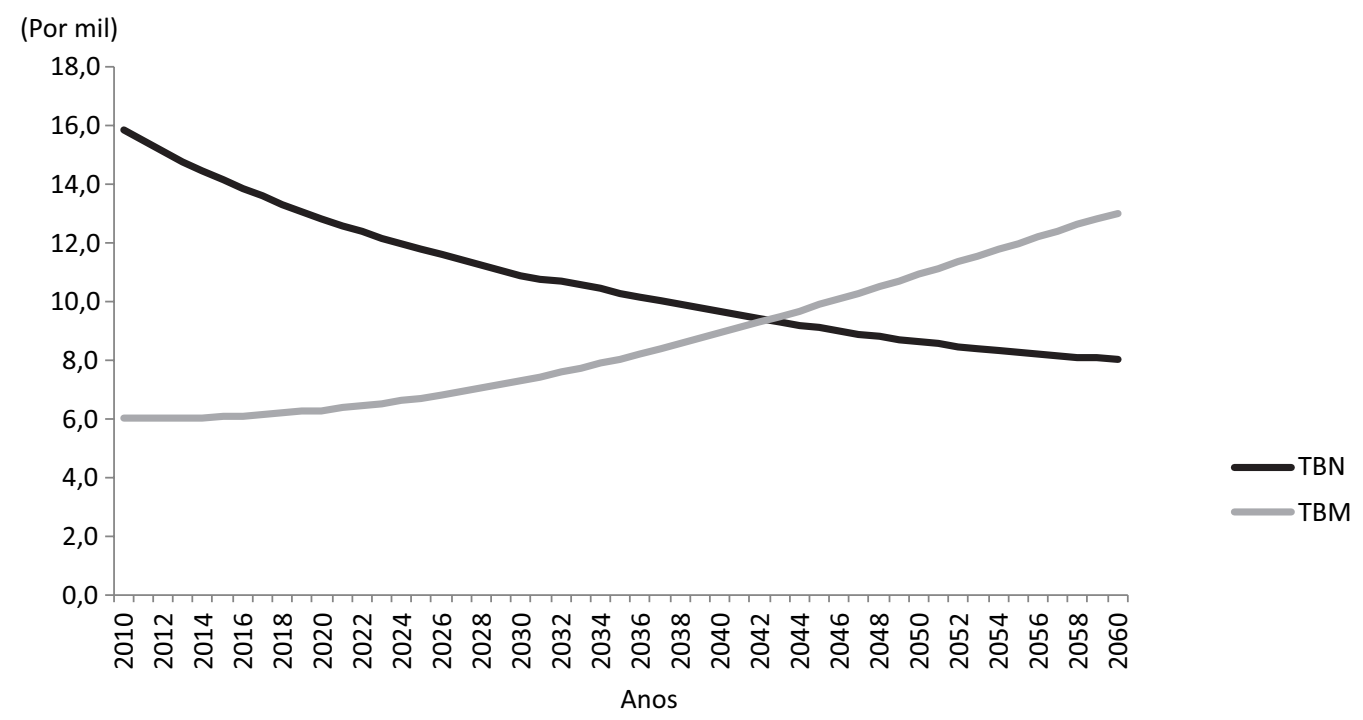

Fonte: elaboração dos autores com base em IBGE, 2013b.

Gráfico 2 - População residente em milhões. Brasil - 2010-2060

(Pop. em milhões)

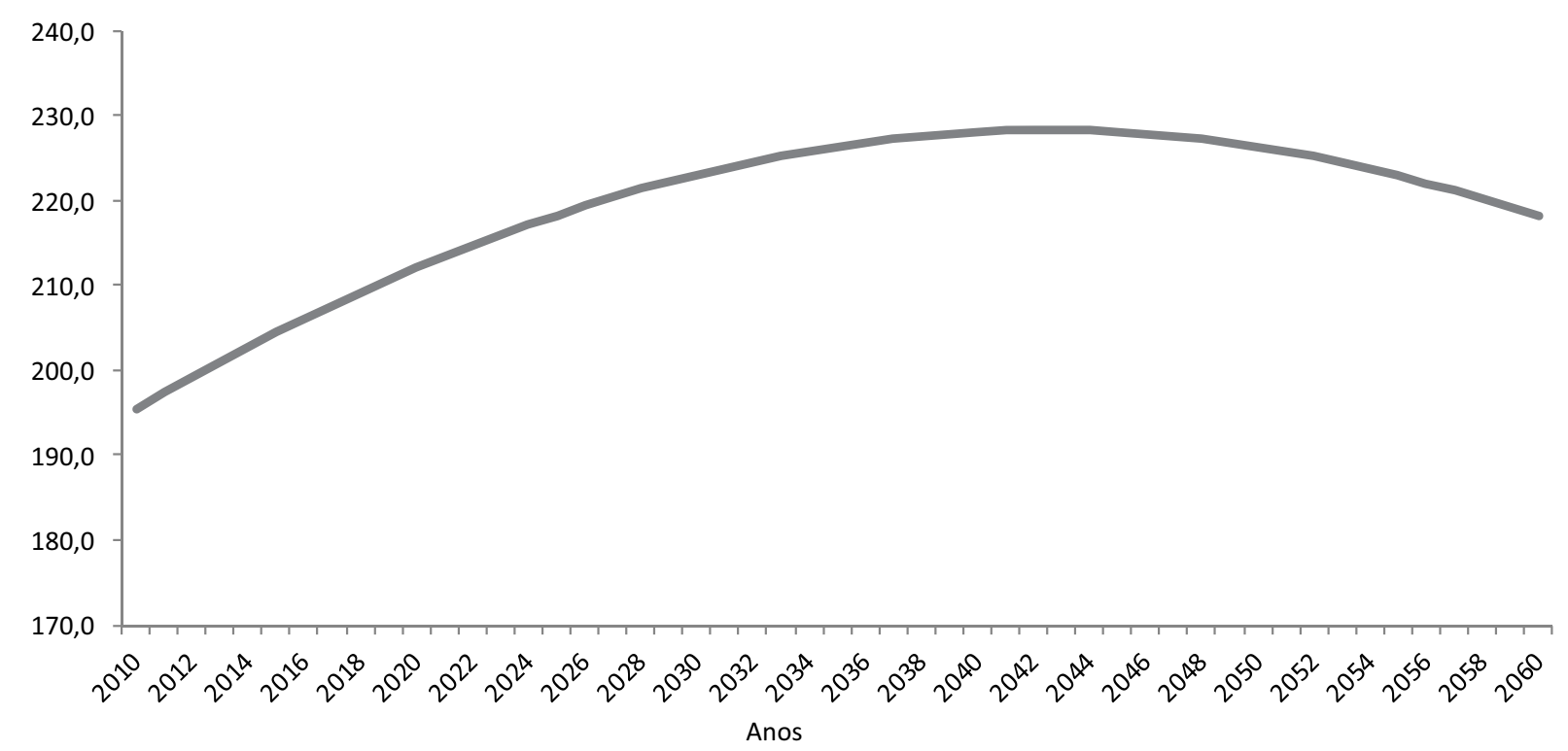

Fonte: elaboração dos autores com base em IBGE, 2013b. 
No que diz respeito aos indicadores sínteses da mortalidade, E0 e TMI, observamos que o primeiro não se alterará muito, estima-se que alcance o patamar de 78,6 anos em 2030, ou seja, um ganho de alguns meses em relação à estimativa anterior. Para a mortalidade infantil, entretanto, espera-se uma melhora significativa, como assinalamos em estudo anterior (Oliveira \& O'Neill, 2013). Esse indicador parte de 17,2 óbitos infantis para cada 1.000 vivos, em 2010, contra 21,6 óbitos no primeiro ano de vida, da estimativa anterior, chegando a uma TMI de nove óbitos infantis para cada 1.000 nascidos vivos. Com essa revisão, mais próxima da realidade, o Brasil atingiu a meta dos Objetivos do Milênio (ODMs), de 15 óbitos infantis, entre 2013 e 2014, antes, portanto, do prazo previsto pelos ODMs, que seria em 2015.

Outra novidade da nova projeção, que também havia sido pleiteada no estudo antecedente, diz respeito à incorporação das migrações internacionais, antes não consideradas. Agora estima-se que o Brasil experimentará saldos migratórios positivos, atingindo um ponto máximo entre 2016 e 2020, a partir do qual irá se reduzindo até tornar-se nulo de 2031 em diante. A hipótese é de que, diante do maior dinamismo econômico, a exploração do petróleo no pré-sal, os grandes eventos esportivos etc., observaremos tanto o retorno de brasileiros, que atualmente residem no exterior, como o aumento dos ingressos de pessoas dos países vizinhos, além da vinda de trabalhadores dos países desenvolvidos, que, em decorrência dos efeitos da crise econômica, já estão sendo atraídos, em certa medida, pela demanda por mão de obra qualificada.

Nunca é demais enfatizar que nosso olhar sobre os fenômenos associados à dinâmica demográfica brasileira apresentada anteriormente, como a que será tratada a seguir para as grandes regiões e UFs, parte do pressuposto que esses são produtos das relações sociais e processos históricos (Canales, 2001), que, portanto, respondem ao estágio de desenvolvimento econômico, social e cultural das sociedades onde estão inscritos. Da mesma forma, os cenários futuros que serão estabelecidos partirão dessa mesma lógica, isto quer dizer, responderão às condições concretas da vida social, naquilo que concernerá à determinação na formação econômica e social (Simões, 2006).

\section{Os diferenciais nos níveis da fecundidade}

Para escalas espaciais mais agregadas, como são as grandes regiões e as UFs, tudo indica que o ritmo de crescimento demográfico e a consequente evolução populacional serão ditados, sobretudo, pelo comportamento do nível da fecundidade, com contribuição menor dos componentes mortalidade e migração. Os diferenciais de fecundidade refletirão a velocidade com que cada uma das escalas espaciais analisadas evoluirá demograficamente.

A região Norte, que historicamente sempre apresentou as maiores TFTs, permaneceu como a única grande região na qual o nível da fecundidade se encontrava acima do de reposição, registrando, em 2010, uma TFT de 2,4 filhos por mulher; apenas Rondônia apresentava nível de fecundidade abaixo do de reposição $(1,96)$. Todas as demais UFs experimentavam taxas superiores a 2,1 filhos por mulher. Segundo as projeções populacionais vigentes, os níveis de fecundidade que não assegurariam a reposição populacional seriam alcançados inicialmente pela UF de Tocantins $(2,07)$, em 2012, 
estando previsto que a região Norte apresentaria TFT de 2,06, em 2016, e o Acre seria a última UF a chegar a esse patamar, em 2022, com 2,05 filhos por mulher. De acordo com as projeções, a TFT para as mulheres do Norte seria em média de 1,64 filho.

No Nordeste, em que pesem todas as assimetrias de desenvolvimento econômico e social, apenas duas UFs estavam, em 2010, com níveis de fecundidade acima do de reposição: Maranhão $(2,47)$ e Alagoas (2,22). A TFT média da região era de 2,02 filhos por mulher. Isto facilitou a convergência de todas as UFs para níveis inferiores ao de reposição, que seria alcançado por Alagoas (2,04), em 2013, e Maranhão $(2,07)$, em 2017. O que chama a atenção para o caso do Nordeste é que a estimativa para a fecundidade média da região (1,57 filho) é bem próxima às dos estados do Centro-Sul para o ano de 2030.

As regiões Sudeste e Sul são as que apresentavam os menores níveis de fecundidade, e todas as UFs registravam taxas ao redor de 1,7 filho por mulher, já para o ano de 2010. As estimativas sinalizam que as TFTs para o ano de 2030 serão de 1,45, bem próximas às dos países europeus que experimentam as mais baixas fecundidades.

No Centro-Oeste, embora a média da TFT $(1,83)$ estivesse, em 2010, abaixo do nível de reposição, duas UFs - Mato Grosso do Sul e Mato Grosso - apresentavam comportamento mais próximo ao do Nordeste, com taxas ao redor de 2,1; já Goiás e o Distrito Federal se assemelhavam ao Sudeste, com TFTs em torno de 1,7 filho por mulher. Para o ano 2030, estima-se que nesta região o nível da fecundidade atingirá valores entre 1,45 e 1,55 filho por mulher.

Em suma, ao se confirmarem os prognósticos implícitos na projeção oficial, as TFTs em todas as UFs, como demonstrado na Tabela 1, irão convergir para níveis semelhantes aos observados nos países desenvolvidos, que se encontram abaixo do patamar necessário para a reposição populacional. A Figura 2 mostra que, enquanto no ano de 2010 as taxas por UF se distribuíam por três faixas de valores, observando-se que em 17 estados estavam acima ou próximas ao nível de reposição, para 2030 o cenário se alterará completamente, quando nove estados do Centro-Sul apresentarão taxas abaixo de 1,5 filho por mulher e nos demais a TFT não ultrapassará o nível de 1,9. Em consequência, questões decorrentes da diminuição das taxas de natalidade, tais como redução do volume da população em idade ativa e envelhecimento irão se generalizar em todo o território nacional num horizonte curto de tempo. 
Tabela 1 - Taxa de fecundidade total, segundo Brasil, grandes regiões e unidades da federação 2010-2030

\begin{tabular}{|c|c|c|c|c|c|}
\hline \multirow{2}{*}{$\begin{array}{l}\text { Brasil, grandes regiões } \\
\text { e unidades da federação }\end{array}$} & \multicolumn{5}{|c|}{ Anos } \\
\hline & 2010 & 2015 & 2020 & 2025 & 2030 \\
\hline BRASIL & 1,87 & 1,72 & 1,61 & 1,55 & 1,51 \\
\hline Norte & 2,40 & 2,11 & 1,90 & 1,74 & 1,64 \\
\hline Rondônia & 1,96 & 1,77 & 1,65 & 1,59 & 1,55 \\
\hline Acre & 2,81 & 2,45 & 2,15 & 1,92 & 1,75 \\
\hline Amazonas & 2,59 & 2,26 & 1,99 & 1,79 & 1,65 \\
\hline Roraima & 2,58 & 2,20 & 1,93 & 1,76 & 1,65 \\
\hline Pará & 2,38 & 2,10 & 1,89 & 1,75 & 1,65 \\
\hline Amapá & 2,69 & 2,27 & 1,98 & 1,80 & 1,70 \\
\hline Tocantins & 2,18 & 1,93 & 1,77 & 1,66 & 1,60 \\
\hline Nordeste & 2,02 & 1,82 & 1,69 & 1,61 & 1,57 \\
\hline Maranhão & 2,47 & 2,17 & 1,93 & 1,76 & 1,65 \\
\hline Piauí & 1,97 & 1,77 & 1,65 & 1,58 & 1,55 \\
\hline Ceará & 1,96 & 1,76 & 1,64 & 1,58 & 1,55 \\
\hline Rio Grande do Norte & 1,91 & 1,74 & 1,64 & 1,58 & 1,55 \\
\hline Paraíba & 1,97 & 1,79 & 1,67 & 1,60 & 1,55 \\
\hline Pernambuco & 1,94 & 1,77 & 1,66 & 1,59 & 1,55 \\
\hline Alagoas & 2,22 & 1,94 & 1,77 & 1,66 & 1,60 \\
\hline Sergipe & 1,97 & 1,76 & 1,64 & 1,58 & 1,55 \\
\hline Bahia & 1,89 & 1,74 & 1,64 & 1,58 & 1,55 \\
\hline Sudeste & 1,70 & 1,59 & 1,52 & 1,48 & 1,45 \\
\hline Minas Gerais & 1,72 & 1,59 & 1,52 & 1,47 & 1,45 \\
\hline Espírito Santo & 1,75 & 1,63 & 1,54 & 1,49 & 1,45 \\
\hline Rio de Janeiro & 1,68 & 1,58 & 1,52 & 1,48 & 1,45 \\
\hline São Paulo & 1,70 & 1,59 & 1,52 & 1,48 & 1,45 \\
\hline Sul & 1,70 & 1,59 & 1,52 & 1,47 & 1,45 \\
\hline Paraná & 1,76 & 1,63 & 1,54 & 1,49 & 1,45 \\
\hline Santa Catarina & 1,65 & 1,55 & 1,50 & 1,47 & 1,45 \\
\hline Rio Grande do Sul & 1,67 & 1,56 & 1,50 & 1,47 & 1,45 \\
\hline Centro-Oeste & 1,83 & 1,69 & 1,60 & 1,53 & 1,49 \\
\hline Mato Grosso do Sul & 2,02 & 1,86 & 1,73 & 1,63 & 1,55 \\
\hline Mato Grosso & 2,01 & 1,85 & 1,72 & 1,62 & 1,55 \\
\hline Goiás & 1,74 & 1,61 & 1,53 & 1,48 & 1,45 \\
\hline Distrito Federal & 1,65 & 1,56 & 1,50 & 1,47 & 1,45 \\
\hline
\end{tabular}

Fonte: elaboração dos autores com base em IBGE, 2013b. 
Figura 2 - Taxa de fecundidade total, segundo unidades da federação. Brasil - 2010 e 2030

Brasil 2010

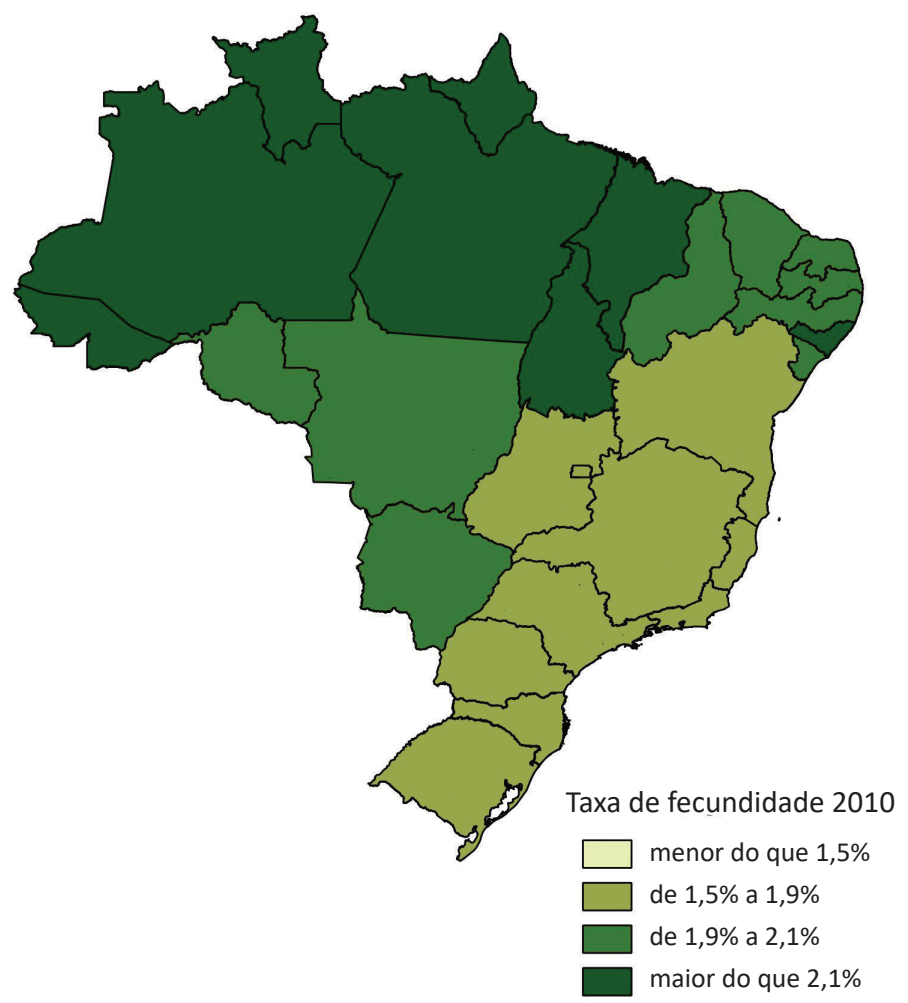

Brasil 2030

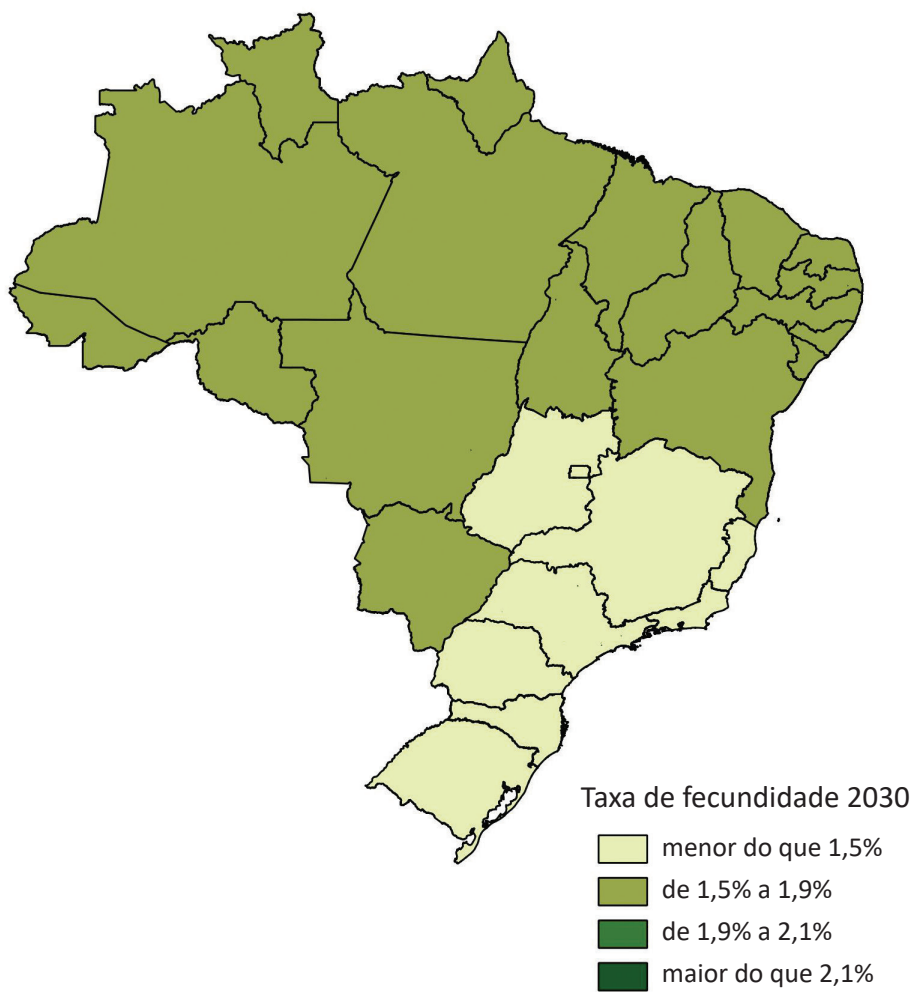

Fonte: elaboração dos autores com base em IBGE, 2013b.

\section{Características gerais da população}

Os indicadores de RDT e E0, que resultam diretamente da evolução das taxas de fecundidade, possibilitam perceber de forma mais nítida a diversidade e os diferenciais regionais na transição demográfica brasileira, corroborando a tese de que a dinâmica demográfica reflete o desenvolvimento econômico, social e cultural das respectivas sociedades.

No caso brasileiro, observa-se claramente que o Sudeste e o Sul se encontram num estágio mais avançado da transição demográfica. Espera-se o aumento nas razões de dependência já nos anos 2010, enquanto o Norte e o Nordeste ainda têm um período de tempo mais longo a usufruir da chamada "janela de oportunidade" demográfica, uma vez que a razão de dependência seguirá diminuindo, em boa parte das UFs, até o horizonte da projeção, em 2030. O Centro-Oeste atravessa um estágio intermediário, contudo mais próximo da realidade do Norte-Nordeste, dado que o IE, apesar da trajetória ascendente, apresentará, na composição do indicador, uma maior participação do segmento jovem, ao passo que as RDTs reverterão a tendência de queda ainda na presente década, num modelo mais semelhante ao do Sudeste-Sul. 
Em relação às razões de dependência, apresentadas na Tabela 2, é importante ressaltar que para aquelas UFs nas quais a etapa da transição demográfica está mais adiantada, no horizonte da projeção, em 2050, espera-se que as RDTs sejam próximas às constatadas no início do período, em 2010, sobretudo no Centro-Oeste, destacando-se que o segmento de idosos passará a ter maior participação na composição do indicador, o que resultará em uma mudança qualitativa importante.

Decompondo-se o indicador RDT por segmento jovem e idoso, observaremos que, mesmo no período no qual a tendência de indicador será de queda, a parcela da população com 60 anos ou mais de idade crescerá de forma ininterrupta, enquanto os de 0 a 14 anos apresentam comportamento contrário. Entre outros fatores de relevada importância, e que estão associados às RDIs, destaca-se um que está diretamente ligado ao crescimento econômico, devido à exaustão do aumento da oferta de força de trabalho, implicando uma redução da taxa de poupança, e consequentemente, refletindo no processo de acumulação do capital. Estudo de Pereima e Porsse (2013) mostra que, quando a RDI supera os $12 \%$, para que seja mantido o ciclo de acumulação, o desenvolvimento econômico dependerá das inovações tecnológicas e dos ganhos de produtividade da força de trabalho.

Tabela 2 - Razão de dependência total, segundo Brasil, grandes regiões e unidades da federação 2010-2030

\begin{tabular}{|l|l|l|l|l|l|}
\hline \multicolumn{1}{|c|}{$\begin{array}{c}\text { Brasil, grandes regiões } \\
\text { e unidades da federação }\end{array}$} & \multicolumn{5}{c|}{ Anos } \\
\hline BRASIL & 2010 & 2015 & 2020 & 2025 & 2030 \\
\hline Norte & 55,20 & 53,61 & 53,16 & 54,51 & 56,77 \\
\hline Rondônia & 63,33 & 58,42 & 53,95 & 51,12 & 49,99 \\
\hline Acre & 53,81 & 50,09 & 47,15 & 47,03 & 48,46 \\
\hline Amazonas & 70,54 & 64,72 & 58,84 & 54,37 & 51,83 \\
\hline Roraima & 65,70 & 59,93 & 55,09 & 51,56 & 49,29 \\
\hline Pará & 65,64 & 59,62 & 53,73 & 50,26 & 48,64 \\
\hline Amapá & 63,61 & 58,94 & 54,63 & 51,65 & 50,44 \\
\hline Tocantins & 68,44 & 61,15 & 53,93 & 49,82 & 48,61 \\
\hline Nordeste & 61,08 & 57,02 & 53,04 & 51,25 & 51,53 \\
\hline Maranhão & 60,00 & 56,74 & 53,97 & 53,33 & 54,35 \\
\hline Piaú́ & 68,54 & 64,60 & 59,26 & 54,77 & 52,28 \\
\hline Ceará & 60,91 & 58,01 & 54,22 & 52,91 & 53,71 \\
\hline Rio Grande do Norte & 60,41 & 56,02 & 52,93 & 52,98 & 54,48 \\
\hline Paraíba & 57,67 & 54,32 & 51,91 & 52,66 & 54,74 \\
\hline Pernambuco & 60,16 & 57,98 & 55,28 & 54,59 & 55,48 \\
\hline Alagoas & 58,63 & 55,82 & 53,41 & 53,36 & 55,03 \\
\hline Sergipe & 63,82 & 59,59 & 55,54 & 53,80 & 54,33 \\
\hline Bahia & 58,26 & 53,89 & 50,31 & 50,06 & 51,89 \\
\hline
\end{tabular}


Tabela 2 - Razão de dependência total, segundo Brasil, grandes regiões e unidades da federação 2010-2030 (cont.)

\begin{tabular}{|l|l|l|l|l|l|}
\hline \multicolumn{1}{|c|}{$\begin{array}{c}\text { Brasil, grandes regiões } \\
\text { e unidades da federação }\end{array}$} & 2010 & 2015 & 2020 & 2025 & 2030 \\
\hline Sudeste & 52,26 & 51,83 & 53,02 & 55,86 & 59,26 \\
\hline Minas Gerais & 53,37 & 52,49 & 53,24 & 55,85 & 58,97 \\
\hline Espírito Santo & 51,42 & 50,65 & 51,64 & 53,82 & 56,48 \\
\hline Rio de Janeiro & 53,71 & 53,13 & 54,96 & 58,41 & 61,95 \\
\hline São Paulo & 51,27 & 51,15 & 52,35 & 55,14 & 58,71 \\
\hline Sul & 52,66 & 52,42 & 53,99 & 57,74 & 61,62 \\
\hline Paraná & 53,22 & 52,39 & 53,06 & 56,01 & 59,92 \\
\hline Santa Catarina & 49,22 & 48,71 & 50,52 & 54,36 & 58,06 \\
\hline Rio Grande do Sul & 54,16 & 54,80 & 57,27 & 61,93 & 66,07 \\
\hline Centro-Oeste & 51,22 & 49,45 & 48,72 & 49,97 & 52,31 \\
\hline Mato Grosso do Sul & 54,94 & 53,99 & 53,50 & 54,47 & 55,94 \\
\hline Mato Grosso & 52,37 & 51,17 & 50,44 & 51,24 & 53,07 \\
\hline Goiás & 51,36 & 49,18 & 47,94 & 49,03 & 51,46 \\
\hline Distrito Federal & 46,25 & 44,30 & 44,70 & 47,08 & 50,48 \\
\hline
\end{tabular}

Fonte: elaboração dos autores com base em IBGE, 2013b.

Na Figura 3, observamos que, em 2010, apenas os estados da região Norte, Mato Grosso e o Distrito Federal, nos quais o processo de envelhecimento populacional está mais retardado, experimentavam RDIs inferiores a $12 \%$. No entanto, a previsão para 2030 é de que em todas as UFs o indicador supere os $12 \%$, e nos estados do Sudeste e do Sul as RDIs sejam superiores a 30\%. Esse cenário impõe que políticas educacionais e econômicas sejam implementadas, de modo que o país possa gerar inovações tecnológicas, as quais produzam ganhos de produtividade que venham a compensar o inexorável envelhecimento populacional, possibilitando que o Brasil alcance um desenvolvimento econômico e social sustentado. 
Figura 3 - Razão de dependência total segundo unidades da federação. Brasil - 2010 e 2030

Brasil 2010

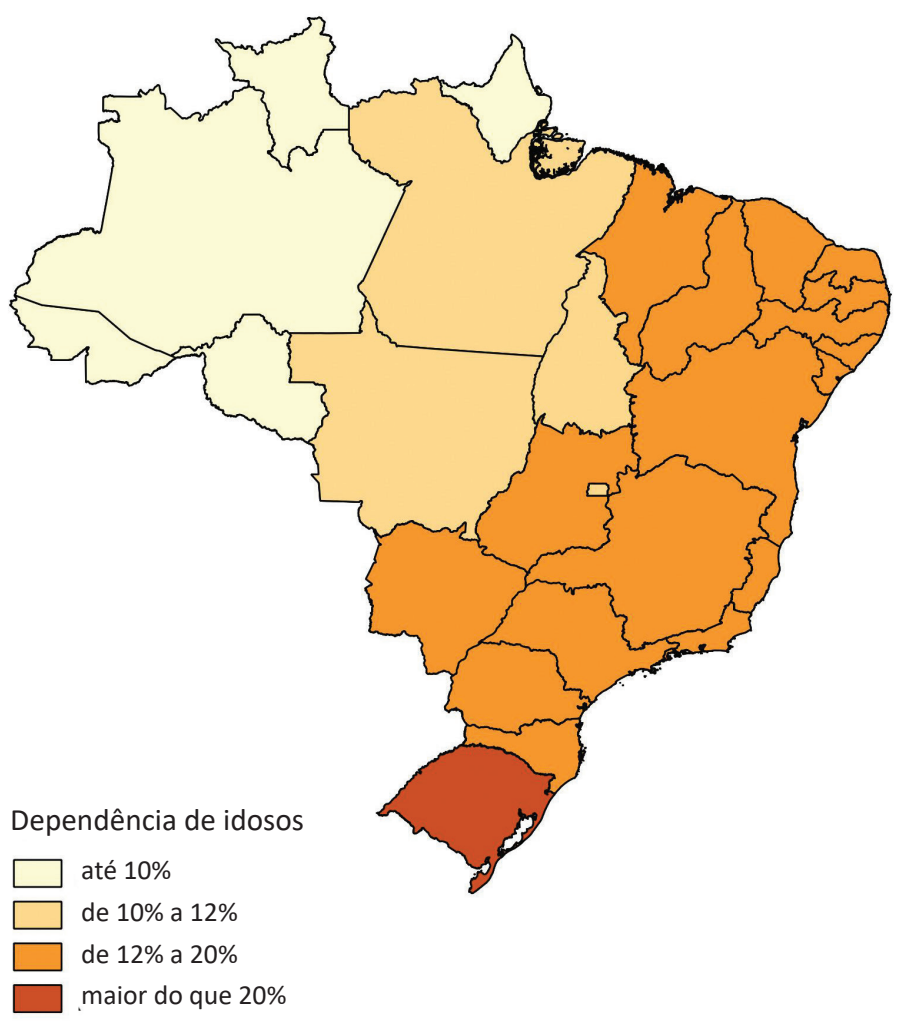

Brasil 2030

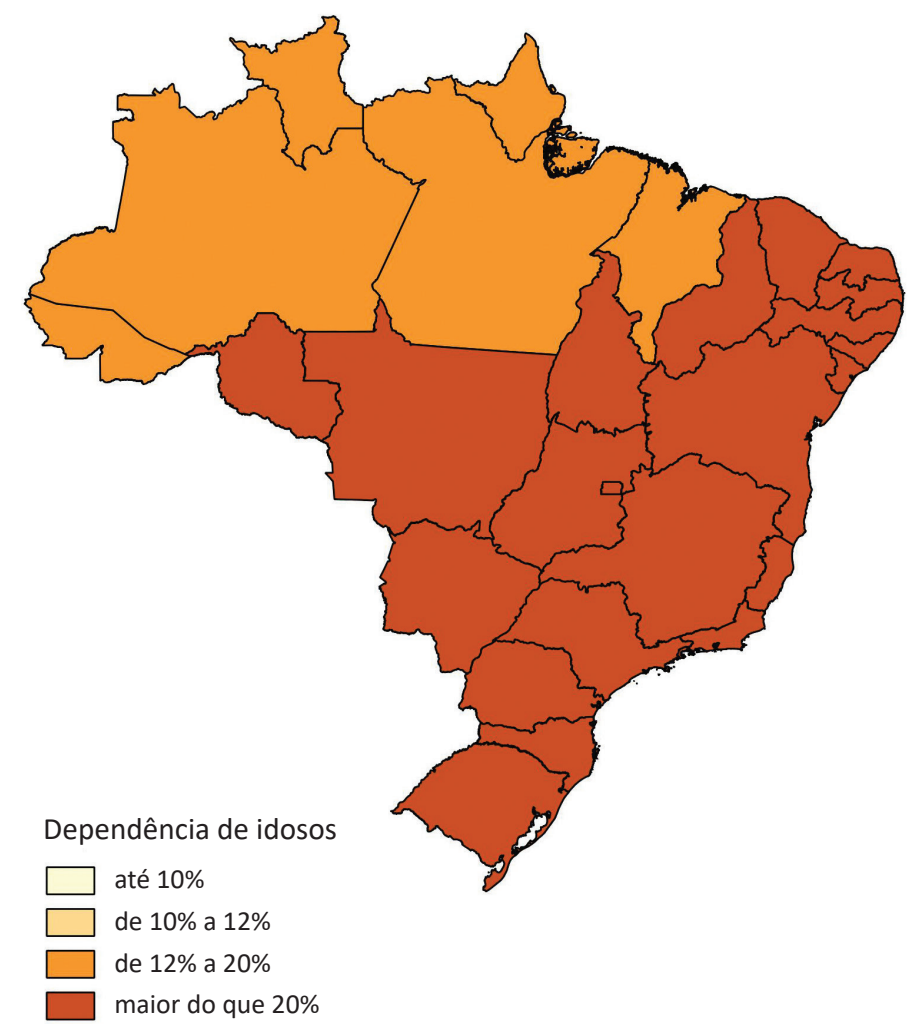

Fonte: elaboração dos autores com base em IBGE, 2013b.

No que diz respeito ao IE, observaremos uma trajetória generalizada de aumento em todo o território nacional. No Rio Grande do Sul, Rio de Janeiro e São Paulo, o fenômeno será mais intenso, dado que, no início dos anos 2020, o volume de população idosa superará o segmento jovem. Para os demais estados do Sudeste e do Sul, isto só ocorrerá mais para o final dessa década. Já nas UFs do Norte, Nordeste e do Centro-Oeste, o processo de envelhecimento ficará um pouco mais lento, resguardando-se o ritmo diferencial, sendo ligeiramente mais acentuado no Rio Grande do Norte, Bahia, Mato Grosso do Sul, Mato Grosso, Goiás e Distrito Federal, como demonstrado na Tabela 3. 
Tabela 3 - Índice de envelhecimento, segundo Brasil, grandes regiões e unidades da federação 2010-2013

\begin{tabular}{|c|c|c|c|c|c|}
\hline \multirow{2}{*}{$\begin{array}{l}\text { Brasil, grandes regiões } \\
\text { e unidades da federação }\end{array}$} & \multicolumn{5}{|c|}{ Anos } \\
\hline & 2010 & 2015 & 2020 & 2025 & 2030 \\
\hline BRASIL & 39,26 & 50,50 & 66,10 & 85,17 & 105,82 \\
\hline Norte & 18,42 & 23,65 & 31,48 & 42,04 & 55,07 \\
\hline Rondônia & 22,25 & 29,58 & 41,06 & 56,01 & 72,84 \\
\hline Acre & 15,91 & 19,82 & 25,86 & 33,92 & 44,84 \\
\hline Amazonas & 15,04 & 19,41 & 25,93 & 35,31 & 47,06 \\
\hline Roraima & 12,78 & 17,56 & 24,93 & 34,69 & 46,12 \\
\hline Pará & 19,59 & 25,01 & 32,95 & 43,43 & 56,50 \\
\hline Amapá & 12,14 & 16,39 & 23,38 & 32,91 & 44,67 \\
\hline Tocantins & 24,41 & 30,91 & 40,65 & 53,48 & 68,90 \\
\hline Nordeste & 32,13 & 39,49 & 50,62 & 65,67 & 83,09 \\
\hline Maranhão & 22,59 & 26,87 & 33,85 & 43,94 & 56,51 \\
\hline Piauí & 31,28 & 38,82 & 50,99 & 66,79 & 83,94 \\
\hline Ceará & 33,87 & 41,97 & 53,17 & 68,41 & 85,30 \\
\hline Rio Grande do Norte & 36,43 & 43,98 & 56,11 & 73,31 & 92,04 \\
\hline Paraíba & 39,22 & 45,44 & 55,67 & 70,97 & 88,96 \\
\hline Pernambuco & 34,72 & 42,46 & 54,52 & 70,62 & 88,96 \\
\hline Alagoas & 25,61 & 32,50 & 42,68 & 56,53 & 73,11 \\
\hline Sergipe & 27,75 & 35,11 & 46,12 & 60,23 & 76,21 \\
\hline Bahia & 34,46 & 43,35 & 56,24 & 72,74 & 92,20 \\
\hline Sudeste & 48,54 & 63,71 & 83,90 & 107,03 & 131,03 \\
\hline Minas Gerais & 46,64 & 60,73 & 80,22 & 103,25 & 127,25 \\
\hline Espírito Santo & 39,20 & 52,56 & 70,44 & 91,57 & 114,07 \\
\hline Rio de Janeiro & 55,59 & 72,98 & 94,23 & 117,12 & 139,21 \\
\hline São Paulo & 47,72 & 62,86 & 83,26 & 106,70 & 131,51 \\
\hline Sul & 50,13 & 66,28 & 87,04 & 111,19 & 135,55 \\
\hline Paraná & 44,26 & 58,47 & 77,44 & 100,75 & 126,26 \\
\hline Santa Catarina & 44,15 & 59,20 & 77,53 & 99,36 & 121,33 \\
\hline Rio Grande do Sul & 60,00 & 79,26 & 104,06 & 131,20 & 156,50 \\
\hline Centro-Oeste & 32,11 & 42,12 & 56,00 & 73,29 & 92,83 \\
\hline Mato Grosso do Sul & 33,92 & 43,02 & 56,38 & 73,99 & 93,69 \\
\hline Mato Grosso & 27,28 & 35,78 & 48,73 & 65,86 & 85,88 \\
\hline Goiás & 34,33 & 44,34 & 58,64 & 75,96 & 94,78 \\
\hline Distrito Federal & 31,06 & 44,11 & 58,63 & 75,47 & 95,53 \\
\hline
\end{tabular}

Fonte: elaboração dos autores com base em IBGE, 2013b. 
O comportamento esperado para os indicadores RDT e IE sinalizam que o Brasil irá experimentar duas ou três transições demográficas simultâneas. Embora tenhamos que nos preparar para o cenário de envelhecimento populacional, os diferenciais regionais demandarão políticas públicas específicas para cada região. Temos um quadro em que ainda é possível aproveitar o chamado "bônus demográfico", com aumento continuado da oferta da força de trabalho, em decorrência da tendência de crescimento da população em idade ativa. Essa janela ficará mais tempo aberta nos estados do Norte e Nordeste, justamente os que demandam políticas educacionais mais efetivas em infraestrutura e qualidade, onde o investimento pode gerar um melhor aproveitamento do bônus. No Centro-Sul, os investimentos nessa área deveriam estar mais voltados para os aspectos da qualidade, e não da estrutura física. Em contrapartida, os investimentos em saúde, proteção social e cuidados com a população idosa devem ser direcionados, a curto e médio prazos, para as regiões Sudeste e Sul, ficando o Norte e Nordeste para um segundo momento. Já para o Centro-Oeste o ideal é que as políticas nessas áreas sejam combinadas, uma vez que a região experimenta uma etapa da transição intermediária em relação às demais regiões.

\section{Indicadores de mortalidade}

Os indicadores de E0 e a TMI, apresentados, respectivamente, nas Tabelas 4 e 5, conseguem sintetizar, com certa propriedade, o estado geral da saúde da população. Ambos indicadores vêm apresentando resultados positivos nas últimas décadas, refletindo, sobretudo, a melhora nas condições de saúde e vida da população, expressas, entre outros, pelos seguintes fatores: maior capilaridade do Sistema Único de Saúde (SUS); expansão dos serviços de saneamento básico, apesar de ainda tímida; maior acesso aos sistemas previdenciário e de proteção social, em geral; aumento real do salário mínimo; e progressiva redução das desigualdades. Em relação à mortalidade infantil, além dos fatores mencionados, poderíamos agregar a ampliação da Estratégia Saúde da Família (ESF), o aumento das consultas pré-natal e do aleitamento materno, bem como das campanhas específicas voltadas para a redução dos óbitos infantis.

Embora venham diminuindo ao longo do tempo, os diferenciais regionais nesses indicadores ainda se fazem presentes, produto das assimetrias regionais no desenvolvimento econômico e social, como apresentado a seguir.

\section{Esperança de vida ao nascer}

A E0 no Norte do país, estimada para o ano de 2010, era de 70,8 anos. Entre as UFs dessa região, apenas Roraima (69,5 anos) apresentava um indicador inferior a 70,0 anos. No extremo oposto, com o melhor desempenho, aparecia o Acre com 72,3 anos. Projetando-se o comportamento da expectativa de vida para o ano de 2030, espera-se que no Acre, Amapá e Tocantins os valores sejam superiores a 76,0 anos, e as demais UFs fiquem ao redor de 74,0 anos.

No Nordeste, com expectativa de vida média ao redor de 71,2 anos, encontravam-se, em 2010, três estados com E0 inferiores a 70,0 anos: Maranhão $(68,8)$, Piauí $(69,9)$ e Alagoas $(69,2)$, reforçando a forte correlação entre o desempenho do indicador e o desenvolvimento econômico. As demais UFs estavam na faixa entre 71,0 e 74,0 anos. Para 2030, de acordo com a projeção, espera-se uma substantiva 
melhora nesse indicador: Maranhão $(74,0)$ e Piauí $(73,4)$ teriam as menores E0, e os outros estados apresentariam valores superiores a 76,0 anos, destacando-se o Rio Grande do Norte com 78,0 anos.

No Sudeste e no Sul, o Rio de Janeiro apresentou o pior desempenho entre todas as UFs, com E0 estimada, para 2010, em 74,2 anos, o que pode ser atribuído, em boa medida, aos óbitos por causas violentas. Nas demais regiões, a E0 superava os 75 anos. Projetando-se o comportamento do indicador, espera-se que todas as UFs dessas duas grandes regiões apresentem valores próximos ou superiores a 80 anos de vida.

O Distrito Federal destaca-se positivamente entre as UFs da região Centro-Oeste, partindo de uma expectativa de vida de 76,3 anos e chegando ao horizonte da projeção com 80,8 anos. Os demais estados, no início do período analisado, apresentavam valores próximos a 73,0 anos de vida ao nascer, estimando-se que deverão alcançar em 2030 uma esperança de vida entre 76,0 e 78,0 anos.

Tabela 4 - Esperança de vida ao nascer, segundo Brasil, grandes regiões e unidades da federação 2010-2013

\begin{tabular}{|l|l|l|l|l|l|}
\hline \multicolumn{1}{|c|}{ Brasil, grandes regiões } & \multicolumn{3}{|c|}{ Anos } \\
\hline B unidades da federação & 2010 & 2015 & 2020 & 2025 & 2030 \\
\hline Norte & 73,86 & 75,44 & 76,74 & 77,80 & 78,64 \\
\hline Rondônia & 70,79 & 72,00 & 73,06 & 73,97 & 74,76 \\
\hline Acre & 70,11 & 71,14 & 72,09 & 72,96 & 73,75 \\
\hline Amazonas & 71,68 & 73,61 & 75,09 & 76,18 & 76,99 \\
\hline Roraima & 70,37 & 71,67 & 72,81 & 73,81 & 74,67 \\
\hline Pará & 69,49 & 71,22 & 72,69 & 73,93 & 74,95 \\
\hline Amapá & 70,87 & 71,91 & 72,83 & 73,66 & 74,39 \\
\hline Tocantins & 72,13 & 73,66 & 74,88 & 75,82 & 76,55 \\
\hline Nordeste & 71,56 & 73,11 & 74,39 & 75,42 & 76,24 \\
\hline Maranhão & 71,23 & 72,81 & 74,13 & 75,23 & 76,13 \\
\hline Piauí & 68,75 & 70,28 & 71,67 & 72,93 & 74,04 \\
\hline Ceará & 69,92 & 70,87 & 71,76 & 72,60 & 73,38 \\
\hline Rio Grande do Norte & 72,40 & 73,62 & 74,68 & 75,60 & 76,37 \\
\hline Paraíba & 74,10 & 75,48 & 76,57 & 77,41 & 78,04 \\
\hline Pernambuco & 71,24 & 72,93 & 74,36 & 75,54 & 76,51 \\
\hline Alagoas & 71,13 & 73,48 & 75,31 & 76,69 & 77,68 \\
\hline Sergipe & 69,18 & 71,23 & 72,98 & 74,45 & 75,65 \\
\hline Bahia & 71,02 & 72,41 & 73,64 & 74,70 & 75,62 \\
\hline Sudeste & 71,92 & 73,23 & 74,36 & 75,32 & 76,13 \\
\hline Minas Gerais & 75,55 & 77,20 & 78,52 & 79,57 & 80,38 \\
\hline Espírito Santo & 75,51 & 76,97 & 78,19 & 79,19 & 79,99 \\
\hline Rio de Janeiro & 75,93 & 77,85 & 79,32 & 80,39 & 81,15 \\
\hline São Paulo & 74,20 & 75,88 & 77,30 & 78,47 & 79,42 \\
\hline
\end{tabular}


Tabela 4 - Esperança de vida ao nascer, segundo Brasil, grandes regiões e unidades da federação 2010-2013 (cont.)

\begin{tabular}{|l|l|l|l|l|l|}
\hline \multicolumn{1}{|c|}{$\begin{array}{c}\text { Brasil, grandes regiões } \\
\text { e unidades da federação }\end{array}$} & 2010 & 2015 & 2020 & 2025 & 2030 \\
\hline Sul & 75,87 & 77,49 & 78,88 & 80,05 & 81,03 \\
\hline Paraná & 75,15 & 76,78 & 78,21 & 79,43 & 80,47 \\
\hline Santa Catarina & 76,93 & 78,74 & 80,21 & 81,37 & 82,26 \\
\hline Rio Grande do Sul & 76,01 & 77,50 & 78,79 & 79,90 & 80,84 \\
\hline Centro-Oeste & 73,69 & 74,90 & 75,97 & 76,91 & 77,73 \\
\hline Mato Grosso do Sul & 73,80 & 75,28 & 76,53 & 77,58 & 78,45 \\
\hline Mato Grosso & 72,64 & 73,97 & 75,17 & 76,22 & 77,15 \\
\hline Goiás & 73,13 & 74,00 & 74,83 & 75,60 & 76,32 \\
\hline Distrito Federal & 76,34 & 77,85 & 79,08 & 80,06 & 80,83 \\
\hline
\end{tabular}

Fonte: elaboração dos autores com base em IBGE, 2013b.

Figura 4 - Esperança de vida ao nascer segundo unidades da federação. Brasil - 2010 e 2030

Brasil 2010

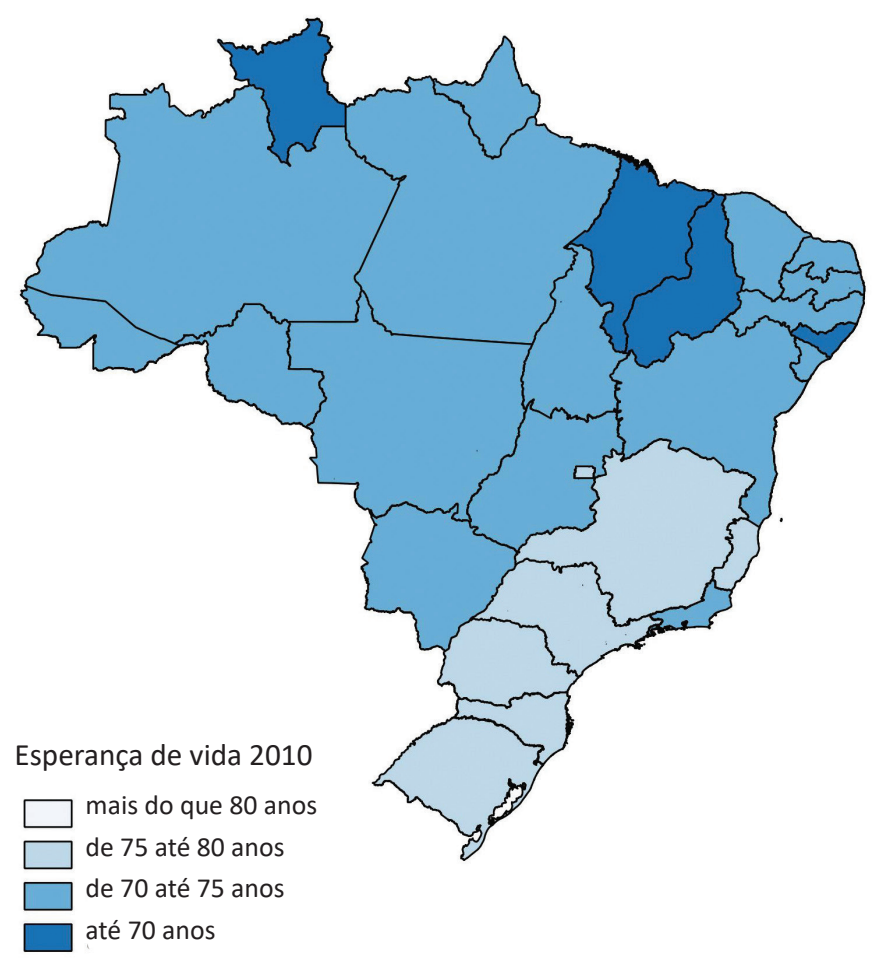

Brasil 2030

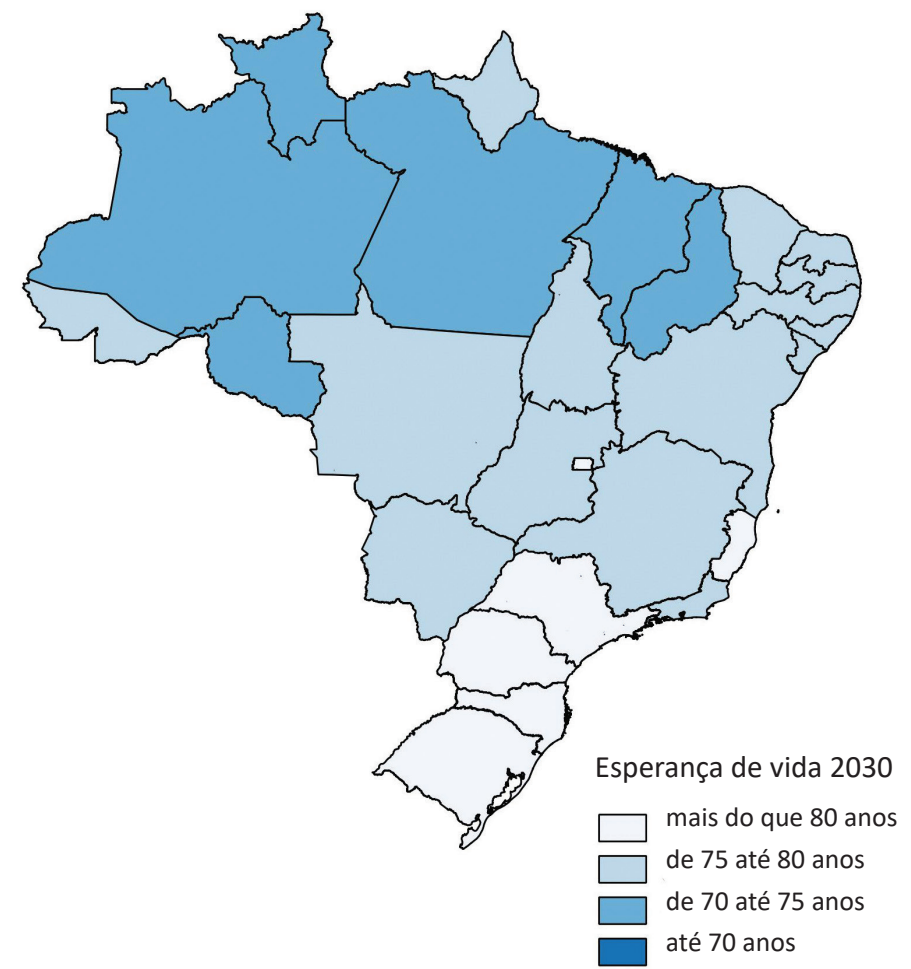

Fonte: elaboração dos autores com base em IBGE, 2013b. 
A Figura 4 mostra a evolução espacial do indicador entre 2010 e 2030 . Quando fazemos a comparação com outros países observamos que, no ponto de partida, algumas poucas UFs do Norte e do Nordeste encontravam-se ligeiramente abaixo da média mundial (70,1 anos), ao passo que as UFs do Sul, Sudeste e o Distrito Federal se acercavam de valores próximos à média dos países desenvolvidos (77,7 anos). Para 2030, espera-se que os estados do Sul, Espírito Santo, São Paulo e o Distrito Federal superem a média dos países desenvolvidos (80,4 anos) e que os demais estados apresentem valores acima do esperado para a média mundial (73,5 anos).

\section{Mortalidade infantil}

O Brasil assumiu como meta, no âmbito dos ODMs, que a TMI, no ano de 2015, seria de 15 óbitos infantis para cada 1.000 nascidos vivos, meta que para a média do país foi atingida em 2013, como já mencionado. Contudo, como podemos observar na Tabela 5 , muitas das UFs ainda estão longe de alcançar esse valor, particularmente aquelas localizadas nas regiões Norte e Nordeste, onde apenas em Roraima $(18,4)$, Tocantins $(19,4)$, Ceará $(19,7)$ e Pernambuco $(18,5)$ a TMI era menor que 20\%o. Os destaques negativos foram os estados do Maranhão (29,0\%o) e Alagoas (30,2\%0). Nesse quadro, a região Norte apenas alcançará o objetivo em 2023, ao passo que no Nordeste isto acontecerá um pouco antes, em 2019. A expectativa positiva para 2030 ficará por conta das UFs do Ceará e Pernambuco, cuja estimativa é de uma TMI de 9,8\% .

As UFs do Centro-Sul e o Distrito Federal já estavam abaixo da meta em 2010, o que deverá ser alcançado pela região Centro-Oeste como um todo dentro do prazo previsto, em 2015. Espera-se que, em 2030, apenas Mato Grosso (12,5\%) e Goiás (10,6\%o) experimentem taxas superiores a $10 \%$.

Comparando-se o indicador com o observado no cenário internacional, embora abaixo da TMI média mundial (37,0\%), em 2010 o Brasil estava muito distante dos países desenvolvidos que registravam, em média, taxas na ordem de 6\%o. A Figura 5 mostra que, em 2010, a maior parte das UFs apresentavam valores superiores a 20\%o (12 UFs) e entre 15 e 20\%o (7 UFs). Em 2030 nos afastaremos bastante da taxa média mundial $(26,0 \%$ ) e nos aproximaremos um pouco mais das taxas a serem experimentadas pelos países desenvolvidos (4,0\%), especialmente os estados do Centro-Sul, onde se espera que o indicador seja da ordem de 6,5\%. 
Tabela 5 - Taxa de mortalidade infantil, segundo Brasil, grandes regiões e unidades da federação 2010-2013

\begin{tabular}{|c|c|c|c|c|c|}
\hline \multirow{2}{*}{$\begin{array}{l}\text { Brasil, grandes regiões } \\
\text { e unidades da federação }\end{array}$} & \multicolumn{5}{|c|}{ Anos } \\
\hline & 2010 & 2015 & 2020 & 2025 & 2030 \\
\hline BRASIL & 17,22 & 13,82 & 11,56 & 10,04 & 9,01 \\
\hline Norte & 21,12 & 18,06 & 15,82 & 14,22 & 13,07 \\
\hline Rondônia & 22,75 & 20,38 & 18,43 & 16,81 & 15,47 \\
\hline Acre & 22,08 & 17,63 & 14,81 & 13,10 & 12,09 \\
\hline Amazonas & 22,20 & 18,77 & 16,26 & 14,45 & 13,18 \\
\hline Roraima & 18,37 & 17,39 & 16,49 & 15,64 & 14,84 \\
\hline Pará & 20,30 & 17,09 & 14,77 & 13,12 & 11,96 \\
\hline Amapá & 24,58 & 23,45 & 22,41 & 21,42 & 20,50 \\
\hline Tocantins & 19,39 & 16,32 & 14,11 & 12,53 & 11,43 \\
\hline Nordeste & 23,08 & 17,50 & 14,17 & 12,22 & 11,08 \\
\hline Maranhão & 29,02 & 22,37 & 17,81 & 14,81 & 12,88 \\
\hline Piauí & 23,45 & 19,72 & 16,98 & 14,89 & 13,30 \\
\hline Ceará & 19,68 & 15,07 & 12,31 & 10,70 & 9,77 \\
\hline Rio Grande do Norte & 20,60 & 15,34 & 12,68 & 11,38 & 10,74 \\
\hline Paraíba & 22,87 & 17,01 & 13,47 & 11,41 & 10,27 \\
\hline Pernambuco & 18,51 & 13,26 & 11,07 & 10,18 & 9,83 \\
\hline Alagoas & 30,22 & 20,86 & 15,56 & 12,78 & 11,40 \\
\hline Sergipe & 22,58 & 17,02 & 13,58 & 11,51 & 10,30 \\
\hline Bahia & 23,13 & 18,11 & 14,89 & 12,88 & 11,64 \\
\hline Sudeste & 13,02 & 10,74 & 9,05 & 7,81 & 6,89 \\
\hline Minas Gerais & 14,63 & 11,41 & 9,18 & 7,65 & 6,60 \\
\hline Espírito Santo & 11,97 & 9,19 & 7,52 & 6,53 & 5,94 \\
\hline Rio de Janeiro & 14,06 & 11,89 & 10,09 & 8,63 & 7,44 \\
\hline São Paulo & 11,98 & 10,16 & 8,77 & 7,71 & 6,91 \\
\hline Sul & 11,61 & 9,72 & 8,22 & 7,04 & 6,12 \\
\hline Paraná & 12,05 & 9,71 & 7,93 & 6,60 & 5,60 \\
\hline Santa Catarina & 11,20 & 9,49 & 8,11 & 7,00 & 6,12 \\
\hline Rio Grande do Sul & 11,39 & 9,88 & 8,62 & 7,56 & 6,69 \\
\hline Centro-Oeste & 16,99 & 14,76 & 12,95 & 11,50 & 10,34 \\
\hline Mato Grosso do Sul & 17,03 & 14,48 & 12,50 & 11,00 & 9,87 \\
\hline Mato Grosso & 19,52 & 17,30 & 15,40 & 13,80 & 12,46 \\
\hline Goiás & 17,71 & 15,35 & 13,41 & 11,84 & 10,58 \\
\hline Distrito Federal & 11,99 & 10,76 & 9,71 & 8,84 & 8,11 \\
\hline
\end{tabular}

Fonte: elaboração dos autores com base em IBGE, 2013b. 
Figura 5 - Taxa de mortalidade infantil segundo unidades da federação. Brasil - 2010-2013
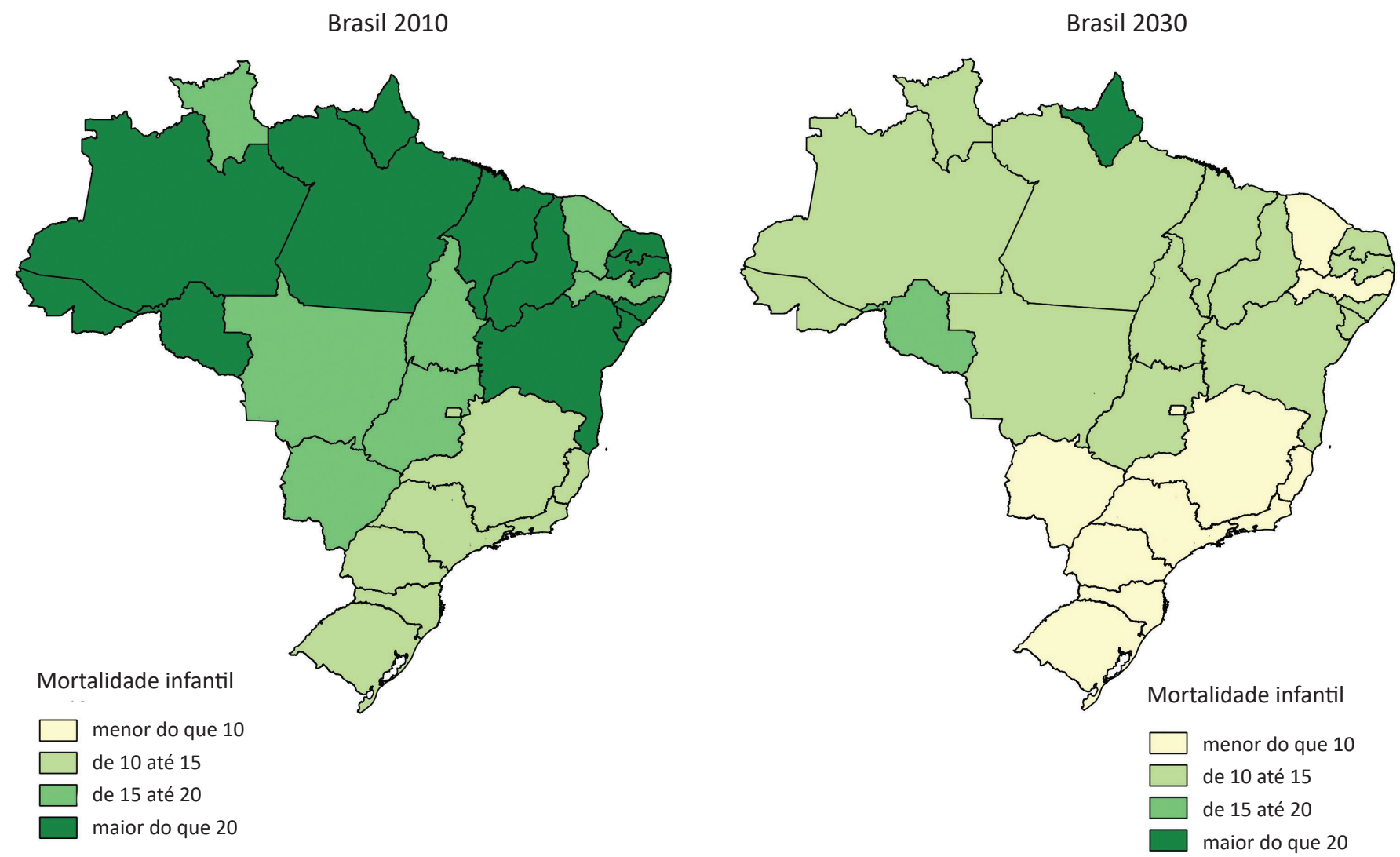

Fonte: elaboração dos autores com base em IBGE, 2013b.

\section{Mobilidade espacial da população}

A mobilidade espacial da população brasileira vem experimentando, a partir dos anos 1980, uma série de transformações, seja na escala interna, seja na internacional. No que tange aos deslocamentos internos, observamos, entre outros, os seguintes aspectos:

1) redução da atratividade migratória exercida pelo estado de São Paulo;

2) volatilidade da corrente principal no estado do Rio de Janeiro;

3) aumento da retenção de população na região Nordeste;

4) migração de retorno;

5) novos eixos de deslocamentos populacionais em direção às cidades médias no interior e nas periferias metropolitanas;

6) perda de importância nas UFs de atração e expulsão na escala das trocas interestaduais;

7) aumento da importância dos deslocamentos pendulares;

8) diminuição na participação relativa das pessoas que se deslocam de um município a outro. 
No que diz respeito às trocas internacionais, o Brasil, que, entre os anos 1930 e 1970, era considerado país fechado à migração, na década de 1980, com a crise econômica, passa a observar a saída expressiva de população para o exterior, sendo estimado que o saldo migratório nessa década fosse negativo em aproximadamente 1,5 milhão de pessoas (Carvalho, 1996; Oliveira et al., 1996). Embora sem números oficiais, imaginava-se que nos anos 1990 o quadro seguiu com perda populacional nas trocas internacionais, fenômeno que viria a ser revertido no final da década de 2000, em virtude da crise econômica mundial, que afetou de forma dramática os países desenvolvidos, em especial aqueles que serviam como principal destino da emigração brasileira (EUA, Japão, Espanha, Portugal, Itália). Os dados do Censo Demográfico de 2010 registraram não só o aumento no retorno de brasileiros, que representou a maior parcela das entradas vindas do exterior, como o acréscimo da chegada de estrangeiros. Além disso, as informações do Ministério do Trabalho e Emprego sinalizam, para os anos 2010, o aumento dos vistos de trabalho para estrangeiros, corroborando hipótese de inversão de tendência no cenário das migrações internacionais (Brasil, 2014).

Em relação aos movimentos internos, observa-se que a participação relativa das pessoas que se deslocam de um município a outro vem diminuindo desde os anos 1980, indicando uma menor mobilidade espacial da população. Na escala mais agregada, embora com fluxos menos volumosos, São Paulo continua atraindo um contingente expressivo de migrantes internos, e a região Nordeste permanece como principal espaço de expulsão de população. Apesar das cidades médias no interior e na periferia das metrópoles passarem a atrair um volume significativo da migração, ainda não superam em volume absoluto o número de migrantes que se dirigem aos grandes centros. Todavia, nas cidades médias, a componente migratória contribui com peso importante para o crescimento demográfico, sobretudo no dinamismo das cidades polos e seu entorno, como pode ser observado na Figura 6.

Para as UFs foram assumidas hipóteses segundo as quais não haverá alterações nos quadros econômicos, sociais e ambientais que possam acarretar mudanças substantivas no comportamento do fenômeno migratório nessas áreas para o período projetado (2010-2030), como pode ser observado na Tabela 6. Nesse sentido, na região Norte, Acre e Pará experimentarão saldos migratórios negativos no período, ao contrário dos demais estados, nos quais os saldos serão positivos.

A região Nordeste continuaria sendo, no período, a única com migração líquida negativa, isso em decorrência dos resultados esperados para o Maranhão, Piauí, Ceará, Paraíba, Pernambuco, Alagoas e Bahia. Já os estados do Rio Grande do Norte e Sergipe seguiriam atraindo população.

Minas Gerais será o único estado da região Sudeste com perda populacional nas trocas migratórias, resultado que deverá ser determinado tanto pela migração interna quanto internacional. Espírito Santo e Rio de Janeiro experimentariam saldos migratórios positivos pouco expressivos, enquanto em São Paulo o saldo será mais expressivo, embora com valores bem menores do que os das décadas passadas. 
Figura 6 - Taxa líquida de migração segundo municípios. Brasil - 2010

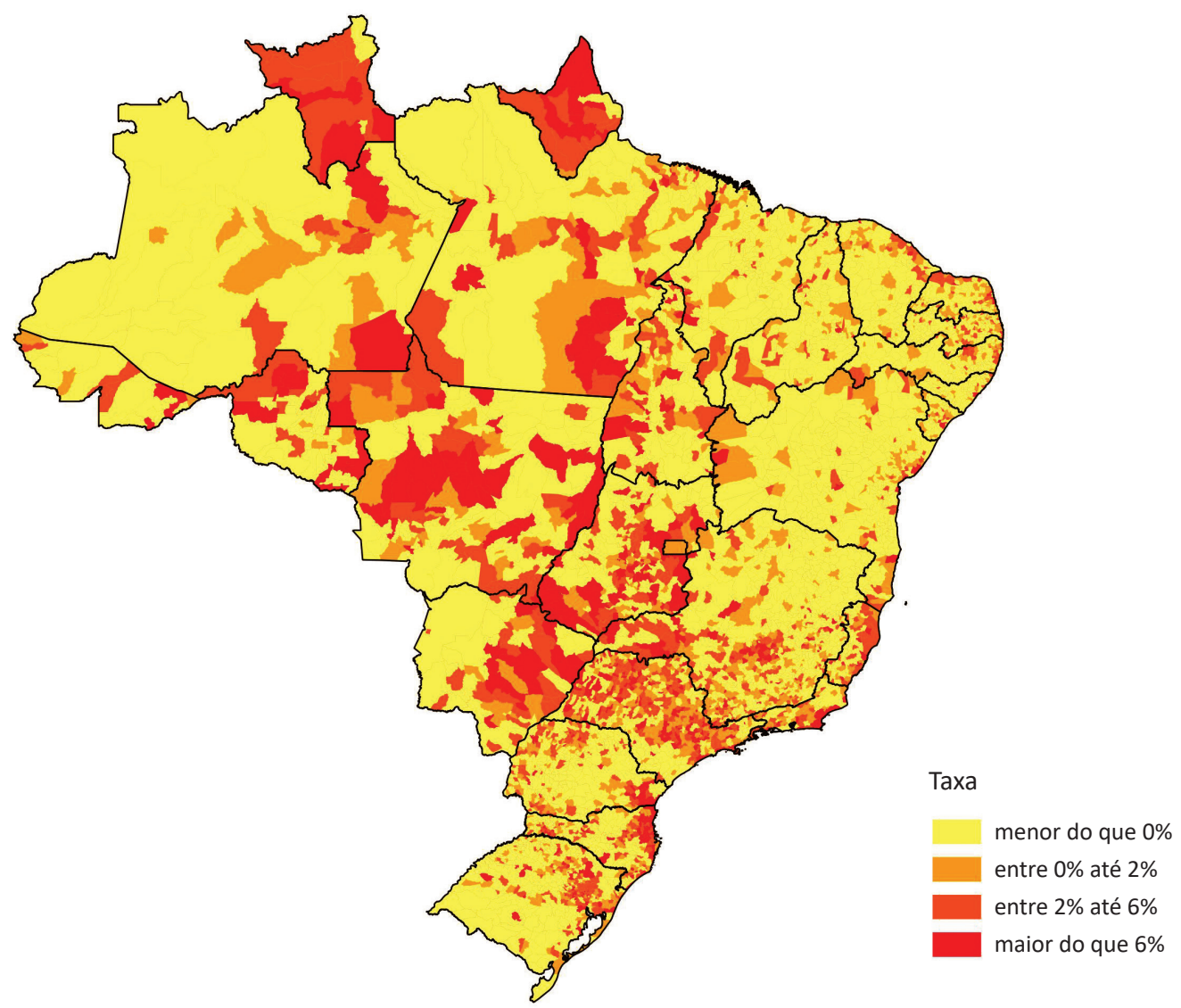

Fonte: elaboração dos autores com base IBGE, 2014c.

A região Sul, apesar de apresentar dois estados com perda líquida migratória, permanecerá atraindo mais do que expulsando migrantes, fruto do desempenho a ser observado em Santa Catarina. O Paraná perderá população na maior parte do tempo, mas passará por um período em que os saldos serão positivos em decorrência dos ganhos com a imigração internacional. Já para o Rio Grande do Sul a expectativa é de saldo negativo para todo o período projetado.

No Centro-Oeste o dinamismo do agronegócio e do centro administrativo de Brasília fará com que a região siga ganhando população nas trocas migratórias. Mato Grosso do Sul e Mato Grosso apresentarão ganhos menos expressivos e Goiás, além de saldos positivos nas trocas internas, também ganhará população com a migração internacional. O Distrito Federal continuará atraindo, no plano interno, um contingente significativo de migrantes.

Em suma, no plano das trocas internas, apesar das importantes transformações observadas no fenômeno, em valores absolutos, São Paulo segue como o principal polo de atração, e o Nordeste, 
a região de onde partem os principais fluxos migratórios, ressaltando-se o aumento da importância relativa das cidades médias. No cenário internacional, o quadro é de incerteza, sobretudo pela volatilidade na dinâmica desses movimentos, em grande medida determinada pelas assimetrias no comportamento da economia mundial.

Tabela 6 - Saldo migratório, segundo Brasil e unidades da federação - 2010-2013

\begin{tabular}{|c|c|c|c|c|c|}
\hline \multirow{2}{*}{$\begin{array}{c}\text { Brasil e } \\
\text { unidades da federação }\end{array}$} & \multicolumn{5}{|c|}{ Anos } \\
\hline & 2010 & 2015 & 2020 & 2025 & 2030 \\
\hline BRASIL & 0 & 3.982 & 8.304 & 5.389 & 4.415 \\
\hline Rondônia & 1.865 & 1.799 & 1.673 & 1.582 & 1.422 \\
\hline Acre & -119 & -123 & -122 & -129 & -128 \\
\hline Amazonas & 3.091 & 3.528 & 3.904 & 3.660 & 3.382 \\
\hline Roraima & 1.025 & 1.023 & 1.018 & 975 & 900 \\
\hline Pará & -7.165 & -7.912 & -8.383 & -7.669 & -6.853 \\
\hline Amapá & 2.986 & 3.180 & 3.337 & 3.394 & 3.374 \\
\hline Tocantins & 667 & 706 & 723 & 766 & 817 \\
\hline Maranhão & -34.274 & -34.387 & -34.201 & -32.254 & -29.583 \\
\hline Piauí & -17.333 & -16.389 & -15.612 & -14.376 & -12.842 \\
\hline Ceará & -18.034 & -17.623 & -16.740 & -15.511 & -14.235 \\
\hline Rio Grande do Norte & 2.652 & 2.653 & 2.602 & 2.591 & 2.567 \\
\hline Paraíba & -4.612 & -4.227 & -4.053 & -3.820 & -3.428 \\
\hline Pernambuco & -12.692 & -13.150 & -13.368 & -12.353 & -11.119 \\
\hline Alagoas & -16.613 & -16.294 & -15.651 & -14.623 & -13.413 \\
\hline Sergipe & 2.076 & 2.105 & 2.112 & 2.151 & 2.178 \\
\hline Bahia & -52.275 & -50.549 & -48.296 & -43.869 & -39.561 \\
\hline Minas Gerais & -4.652 & -8.314 & -10.938 & -9.790 & -8.598 \\
\hline Espírito Santo & 12.938 & 12.075 & 11.221 & 11.077 & 10.805 \\
\hline Rio de Janeiro & 2.311 & 2.767 & 2.708 & 1.155 & -25 \\
\hline São Paulo & 42.193 & 44.416 & 46.826 & 39.379 & 32.195 \\
\hline Paraná & -3.879 & -1.091 & 1.419 & -524 & -1.848 \\
\hline Santa Catarina & 38.793 & 38.690 & 38.236 & 36.496 & 34.660 \\
\hline Rio Grande do Sul & -19.136 & -17.911 & -16.597 & -16.064 & -15.237 \\
\hline Mato Grosso do Sul & 5.011 & 5.511 & 5.895 & 4.865 & 3.960 \\
\hline Mato Grosso & 7.636 & 7.108 & 6.551 & 5.950 & 5.268 \\
\hline Goiás & 36.819 & 34.941 & 33.005 & 33.089 & 32.475 \\
\hline Distrito Federal & 30.723 & 31.450 & 31.035 & 29.239 & 27.279 \\
\hline
\end{tabular}

Fonte: elaboração dos autores com base em IBGE, 2013b. 


\section{A Oferta e o Acesso aos Serviços de Saúde}

\section{A centralidade dos espaços em saúde}

A centralidade em saúde foi identificada mediante associação de dois indicadores: o de complexidade nos centros localizados nas áreas imediatas de articulação urbano-regional e o de tamanho do setor, avaliado pelo volume das internações hospitalares. O de complexidade foi construído com base na existência de equipamentos em saúde e especialidades nas cidades, para determinar o grau de atendimento disponível. O indicador de tamanho utilizado foi o número de internações hospitalares financiadas pelo SUS em 2012. Os dois indicadores correspondem ao conjunto de informações disponíveis na publicação Regiões de Influência das Cidades - 2007 (IBGE, 2008), atualizada para 2009 e com adaptações nos procedimentos. Cabe observar que tal publicação fornece também a hierarquia dos centros urbanos do país, que foi utilizada como mais uma fonte de informação e anexada a esse estudo.

A construção do indicador de nível de complexidade levou em conta 11 tipos de equipamentos e 26 especialidades informadas pelos estabelecimentos. Essas medidas são denominadas indicadores de estoques e representam a capacidade de prestação de serviços de saúde de um centro urbano. Cabe observar que os valores de estoques também são indicativos de processos espaciais, concretizados ou em curso, resultantes de políticas de saúde empreendidas até então. A existência dos instrumentos e das especialidades determina certo grau de disponibilidade de acesso à saúde e, conforme a combinação dos atributos, a complexidade disponível nos centros.

Uma vez selecionados os equipamentos e especialidades que compõem o indicador, direcionou-se o tratamento dos dados para a construção de duas matrizes espaciais como método de apreensão do território. As matrizes possuem os municípios nas linhas e os atributos nas colunas, e a junção das linhas e das colunas forma células com valores em uma localização particular, que, uma vez contabilizados e classificados, permitem assimilar as formas de organização espacial de um dado território.

$\mathrm{Na}$ construção dos indicadores, registrou-se o número de equipamentos e de especialidades médicas que serviram de referência para se obter duas tabelas com a presença dos atributos. Assim, se um município possuísse mais de um equipamento para hemodiálise ou nefrologista, apenas a existência do equipamento ou a especialidade foi registrada.

Em seguida, a presença do equipamento ou da especialidade foi totalizada de forma que se verificou que apenas 60 municípios dispõem da bomba de cobalto, enquanto aparelhos de eletrocardiógrafo podem ser encontrados em 3.680 municípios. Quanto às especialidades, a videolaparoscopia pode ser encontrada em apenas 27 municípios, enquanto clínica médica aparece em 3.626, indicando graus de complexidades variadas entre os municípios. Os Quadros 1 e 2 ilustram a frequência dos equipamentos e especialidades selecionados e trazem a hierarquia definida para cada atributo. 
Quadro1 - Frequência e hierarquia dos equipamentos

\begin{tabular}{|l|c|c|}
\hline \multicolumn{1}{|c|}{ Equipamentos } & Total de municípios & Classes de hierarquia \\
\hline Bomba de cobalto & 60 & 1 \\
\hline Circulação extracorpórea & 121 & 2 \\
\hline Ressonância magnética & 164 & 2 \\
\hline Mamografia com estereotaxia & 175 & 2 \\
\hline Hemodiálise & 359 & 3 \\
\hline Tomógrafo computadorizado & 426 & 3 \\
\hline Eletroencefalógrafo & 552 & 3 \\
\hline Mamógrafo com comando simples & 647 & 3 \\
\hline Ultrassom com doppler colorido & 1.003 & 4 \\
\hline Ultrassom com ecógrafo & 2.025 & 4 \\
\hline Eletrocardiógrafo & 3.680 & 5 \\
\hline
\end{tabular}

Fonte: elaboração dos autores com base em IBGE, 2010.

Quadro 2 - Frequência e hierarquia das especialidades

\begin{tabular}{|l|c|c|}
\hline \multicolumn{1}{r}{ Especialidades } & Total de municípios & Classe de hierarquia \\
\hline Videolaparoscopia & 27 & 1 \\
\hline Quimioterapia & 33 & 1 \\
\hline Medicina nuclear & 92 & 1 \\
\hline Hemodinâmica & 93 & 1 \\
\hline Neurocirurgia & 190 & 2 \\
\hline Hematologia & 210 & 2 \\
\hline Oncologia & 213 & 2 \\
\hline Proctologia & 217 & 2 \\
\hline Reumatologia & 222 & 2 \\
\hline Nefrologia & 331 & 3 \\
\hline Cirurgia plástica & 352 & 3 \\
\hline Pneumologia/Tisiologia & 381 & 3 \\
\hline Angiologia & 433 & 3 \\
\hline Endocrinologia & 573 & 3 \\
\hline Neurologia & 884 & 4 \\
\hline Oftalmologia & 1.082 & 4 \\
\hline Ortopedia e traumatologia & 1.727 & 4 \\
\hline Cirurgia geral & 1.766 & 4 \\
\hline Cardiologia & 1.981 & 4 \\
\hline Obstetrícia & 2.171 & 5 \\
\hline Análises clínicas & 2.813 & 5 \\
\hline
\end{tabular}


Quadro 2 - Frequência e hierarquia das especialidades (cont.)

\begin{tabular}{|c|c|c|}
\hline Especialidades & Total de municípios & Classe de hierarquia \\
\hline Pediatria & 2.995 & 5 \\
\hline Ginecologia & 3.298 & 5 \\
\hline Clínica médica & 3.626 & 5 \\
\hline
\end{tabular}

Fonte: elaboração dos autores com base em IBGE, 2010.

Com base na frequência da distribuição dos equipamentos em condições de uso pelos municípios, os 11 selecionados para compor os indicadores do nível de complexidade em saúde foram alocados em cinco classes. Assim, todos os 3.680 municípios pertenciam à classe 5 , definida pela presença do eletrocardiógrafo, a partir da qual a inclusão é contínua. Para serem classificados nas classes superiores, os municípios teriam que possuir pelo menos um dos equipamentos de cada classe até a primeira classe, em que a presença de bomba de cobalto posicionou, na maior hierarquia, os municípios com esse equipamento.

Procedimento semelhante foi utilizado para classificar as cidades segundo as especialidades disponíveis nos estabelecimentos de saúde ali situados, com cinco especialidades por classe. Os 3.626 municípios com especialidades foram alocados às classes quando dispunham de pelo menos três das especialidades que as definem. Aqueles que não tinham equipamentos ou especialidades receberam a classificação 0 (zero).

Em seguida, as duas classificações foram combinadas com o objetivo de obterem-se os níveis de complexidade (classe complexidade 1) dos centros. A combinação das duas classificações serve para

contornar questões ligadas à possibilidade de um município ter o equipamento disponível sem a presença dos profissionais necessários para sua operação, bem como a de existir o atendimento em determinada especialidade, mas sem ser registrado, por não constituir a principal atividade do estabelecimento. (IBGE, 2008: 136)

A classificação resultou numa hierarquia em seis níveis. Todos os municípios que apresentaram classificação em apenas um dos eixos, ou seja, sem equipamentos ou sem especialidades (resultado 0) formam os municípios classificados no sexto nível.

O número de internações hospitalares pagas pelo SUS em 2012 foi outra informação utilizada para classificar os centros em seis classes. Somente foram classificados os centros que possuíam mais de $0,01 \%$ do volume de internações no total do Brasil, o que significa 92,3\% do total de internações.

A combinação dos indicadores de complexidade e tamanho resultou no índice de centralidade que possui uma escala de 0 (zero) a 6 (seis), sendo 0 a ausência do atributo e, a partir de 1 até 6 , o nível do centro baixa na centralidade em saúde. Os centros que apresentaram 0 num dos indicadores e valor diferente no outro receberam a nota 6 e, na combinação dos índices de complexidade e tamanho, prevaleceu a classe mais alta em que o centro foi classificado; assim, se um centro estava na classe 2 de complexidade e 4 em tamanho, sua centralidade foi 4. 
Outro indicador utilizado refere-se ao número de leitos hospitalares por 1.000 habitantes (IBGE, 2010), que mede a oferta física de leitos hospitalares em relação à população residente nas áreas imediatas de articulação urbano-regional (Quadro 3). Esse indicador pode ser utilizado como uma proxy para a demanda em atendimento hospitalar, uma vez que o número de leitos deve atender as necessidades da população de uma determinada região.

De 1990 a 2009 a média do número de leitos por 1.000 habitantes no país diminuiu de 3,71 para 2,46. De acordo com o Ministério da Saúde, esse comportamento vem ocorrendo em outros países e é resultado não só da ampliação de atendimento ambulatorial, mas também da possibilidade de tratamentos - que, graças às inovações tecnológicas, reduzem a necessidade de internações, dentre eles alguns tratamentos de câncer - além dos investimentos e melhor qualificação na rede pública.

Segundo o estudo feito pela CIA World Factbook, ${ }^{2}$ referente ao número de leitos por habitantes, dos 181 países pesquisados o Japão figura em primeiro lugar, com 13,7/1.000 habitantes; França em

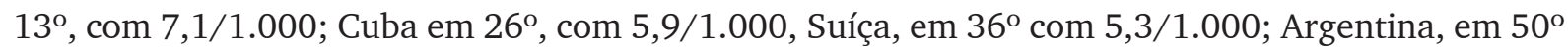
lugar, com 4,0/1.000; Estados Unidos, em 69 ${ }^{\circ}$, com 3,1/1.000; Uruguai, em $77^{\circ}$, com 2,9/1.000 e o Brasil, em $89^{\circ}$, com 2,4/1.000. Esses valores, que não estão correlacionados ao desempenho econômico dos países, indicam, possivelmente, a importância das políticas para o setor empreendidas nas diferentes nações, que envolvem o acesso e a eficiência dos serviços disponibilizados à população.

Ainda que o Brasil apresente grande diversidade regional na prestação de serviços de saúde, existe, da parte de órgãos oficiais como o Ministério da Saúde, a Organização Mundial de Saúde (OMS) e a Organização Pan-Americana de Saúde (Opas), a recomendação de adoção de um intervalo considerado razoável de disponibilidade de leitos para internações, que varia entre 2,5 a 3,0 leitos por 1.000 habitantes. $^{3}$

Quadro 3 - Leitos por 1.333 habitantes. Brasil - 1990-2009

\begin{tabular}{|c|c|}
\hline Período & Leitos \\
\hline 1990 & 3,71 \\
\hline 1992 & 3,66 \\
\hline 1999 & 2,96 \\
\hline 2002 & 2,70 \\
\hline 2005 & 2,41 \\
\hline 2009 & 2,46 \\
\hline
\end{tabular}

Fonte: elaboração dos autores com base em IBGE, 2010.

Com base nas projeções de população, foi possível generalizar os valores das taxas de crescimento populacional e obter áreas de maior e menor dinamismo populacional no país.

\footnotetext{
${ }^{2}$ Disponível em: <www.indexmundi.com/g/r.aspx?c=br\&v=2227\&l=pt $>$. Acesso em: jan. 2014.

${ }^{3}$ Parâmetros para programação das ações básicas de saúde MS. Disponível em: <www.paho.org/bra/index. php?option=com_docman>. Acesso em: jan. 2014.
} 
Cabe observar que, na pesquisa Regiões de Influência das Cidades - 2007 (IBGE, 2008), a hierarquia urbana das cidades que apresentam grandes aglomerações urbanas é formada por um conjunto de municípios denominado áreas de concentração de população (ACPs). As ACPs configuram-se como espaços diferenciados, onde os fenômenos urbanos são intensos, resultando em modelos territoriais mais adequados às novas tendências da urbanização (Castello Branco, 2006). São múltiplas redes que se apoiam nesses centros privilegiados, atravessados por fluxos de todos os tipos, tais como: pessoas, informações, produtos, entre outros. A Figura 7 mostra a distribuição desse recorte territorial no país.

Figura 7 - Áreas de concentração da população - 2009

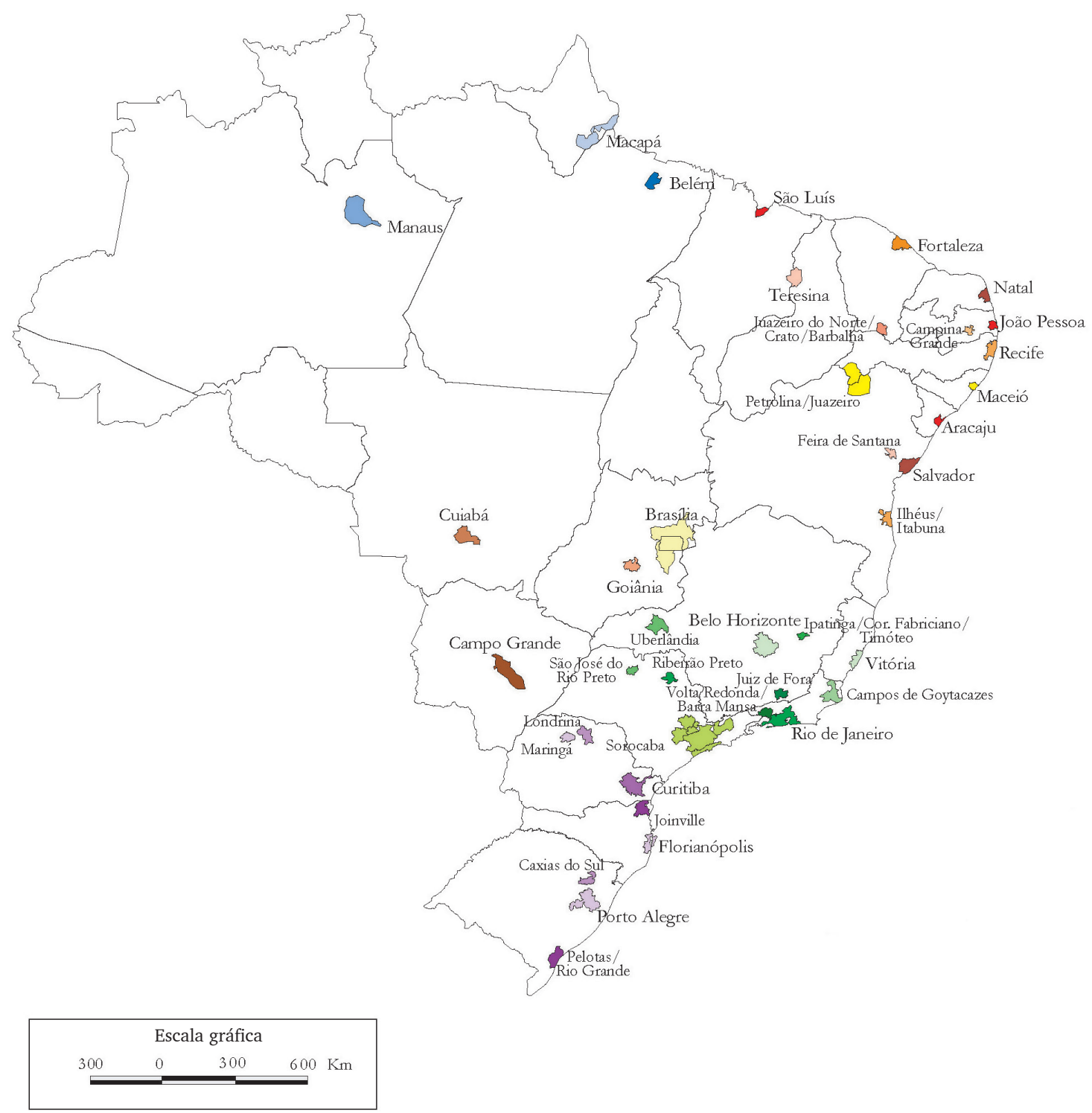

Fonte: elaboração dos autores com base em dados do IBGE - Coordenação de Geografia. 


\section{Resultados}

A incorporação das regiões de articulação imediata, seus polos e os outros centros que compõem cada região são elementos fundamentais para integrar os resultados parciais - classes de especialidade e classe de equipamentos e classe de tamanho, número de leitos por 1.000 habitantes, áreas de maior e menor dinamismo populacional, a centralidade em saúde, associada à hierarquia dos centros urbanos - e assim municiar o processo de tomada de decisão, levando em consideração a localização e as características de cada polo. Tal arquitetura identifica uma rede urbana com funcionalidade e complementaridade entre os centros, vantagens locacionais capazes de imprimir a diferenciação a partir do nível mais alto da hierarquia para os centros dispostos nos níveis inferiores.

Conforme já mencionado, a centralidade resultou em um quadro síntese (Quadro 4) com os níveis de complexidade obtidos a partir da combinação das classes de complexidade e de volume. Num conjunto de 5.567 municípios analisados, 1.132 não possuem centralidade; apenas um, São Paulo, apresenta centralidade máxima, igual a 1; e 3.997 foram classificados com a mais baixa centralidade, que corresponde à centralidade 6 .

Os valores no Quadro 4 ilustram os padrões espaciais de distribuição de bens e serviços em saúde vigentes nas regiões imediatas de articulação urbana e revelam a forte concentração do setor. No tocante à complexidade, apenas 31 centros pesquisados possuem centralidade nas classes de 1 a 3. Os três primeiros níveis de centralidade em saúde caracterizam centros que atuam num nível de atendimento mais complexo, pois foram os melhores classificados em termos de presença de equipamentos e especialidades de maior hierarquia (Quadros 1 e 2), assim como têm os mais altos valores nas internações hospitalares.

Quadro 4 - Níveis de centralidade segundo oferta de serviços de saúde: complexidade e tamanho. Brasil - 2009-2012

\begin{tabular}{|c|c|c|c|c|c|c|c|c|c|c|}
\hline \multirow[t]{2}{*}{$\begin{array}{l}\text { Níveis de } \\
\text { centralidade }\end{array}$} & \multirow[t]{2}{*}{$\begin{array}{l}\text { Número de } \\
\text { municípios }\end{array}$} & \multicolumn{7}{|c|}{ Classes de complexidade } & \multirow{2}{*}{$\begin{array}{c}\text { Classe de } \\
\text { volume }\end{array}$} & \multirow{2}{*}{$\begin{array}{l}\text { Número de } \\
\text { internações } \\
\text { SUS }\end{array}$} \\
\hline & & 1 & 2 & 3 & 4 & 5 & 6 & 0 & & \\
\hline 1 & 1 & 1 & & & & & & & 1 & 676.996 \\
\hline 2 & 10 & 4 & 6 & & & & & & 2 & 256.354 \\
\hline 3 & 20 & 3 & 17 & & & & & & 3 & 185.415 \\
\hline 4 & 64 & 2 & 44 & 13 & 5 & & & & 4 & 18.071 \\
\hline 5 & 342 & 1 & 44 & 122 & 151 & 24 & & & 5 & 1.674 \\
\hline 6 & 10 & & & & & & 9 & 1 & 5 & 1.674 \\
\hline 6 & 913 & & 2 & 41 & 401 & 321 & 126 & 22 & 6 & 1.232 \\
\hline 6 & 3.074 & & 1 & 2 & 257 & 1.339 & 1.475 & & 0 & 0 \\
\hline 0 & 1.132 & & & & & & & 1.132 & 0 & \\
\hline
\end{tabular}

Fonte: elaboração dos autores. 
Ao examinar os resultados parciais das classificações, constata-se que, apesar de poucos municípios possuírem o equipamento de bomba de cobalto, ele está presente em quase todos os municípios com centralidade entre 1 e 3 . O número de internações hospitalares, por sua vez, foi determinante para a definição da centralidade, uma vez que muitos centros com níveis de complexidade média e alta não apresentaram o mesmo resultado na capacidade de internações hospitalares.

Apenas São Paulo alcançou a mais alta centralidade, de nível 1, tanto na complexidade como no volume das internações. Na classe 2 de centralidade podem ser encontrados centros com classificação 1 e 2, em complexidade de equipamento e de especialidade e nível 2 em volume das internações, classificando dez centros. O $3^{\circ}$ nível tem o dobro de centros, vinte ao todo, classificados segundo uma combinação de classes de complexidade 1 e 2 e de volume 3.

As classes de centralidade 2 e 3 qualificam polos em regiões imediatas com hierarquias urbanas que variam de metrópoles a capitais regionais, como Recife (PE), Belo Horizonte (MG), Rio de Janeiro (RJ), Curitiba (PR), Porto Alegre (RS) e Brasília (DF) no $2^{\circ}$ nível, e Belém (PA) Natal (RN), Maceió (AL), Vitória (ES), Sorocaba (SP) e Londrina (PR) no $3^{\circ}$ nível, entre outras. São centros que tradicionalmente já atraem fortemente pessoas que procuram serviços de saúde dos mais sofisticados aos mais simples.

A presença geográfica dos centros com centralidade 4 é maior nas regiões Nordeste e Sudeste, onde se localizam, aproximadamente, $70 \%$ dos centros, caindo, sensivelmente, para as regiões Norte, Sul e Centro-Oeste. Na região Norte, apenas Manaus (AM) e Belém (PA) possuem centralidade 2 e 3, respectivamente. Na região Sul, Curitiba (PR) e Porto Alegre possuem centralidade 2 e Londrina, 3 (Quadro 4). O resultado da pequena presença de centros nos níveis mais altos de centralidade em saúde reflete o processo de macrourbanização brasileiro, em que 49 aglomerações urbanas abrigam quase 50\% dos habitantes urbanos do país e concentram $65 \%$ do Produto Interno Bruto (PIB) nacional.

O $4^{\circ}$ nível de centralidade reúne 64 centros onde predominam condições de atendimento em saúde de média complexidade, nos quais se constata a presença de centros com hierarquias de capitais regionais e centros sub-regionais, a exemplo de Porto Velho (RO), Rio Branco (AC), Boa Vista (RR), Santarém (PA), Palmas (TO), Imperatriz (MA), as ACPs de Macapá (AP), Petrolina-Juazeiro (PE/BA), Ilhéus-Itabuna (BA), Ipatinga-Coronel Fabriciano (MG), Campos dos Goytacazes (RJ), Florianópolis e Joinville (SC) e apenas um centro de zona, que classifica a ACP de Jundiaí (SP), além de alguns centros que conformam ACPs.

A centralidade no $4^{\circ}$ nível já aparece mais representada em centros regionais longamente estabelecidos, conforme os exemplos citados, e resulta da combinação de centros classificados entre a $1^{\mathrm{a}}$ e a $4^{\mathrm{a}}$ classe de complexidade e a $4^{\mathrm{a}}$ classe em volume de internações, uma vez que na definição de centralidade predomina, na combinação, a classe de valor mais elevado. A presença desses centros guarda vinculações com o passado, quando o quadro da economia brasileira e a pouca acessibilidade, devido à precariedade dos transportes, fizeram surgir centros de hierarquia intermediária no sistema urbano, em particular nas regiões Nordeste, Sudeste e Sul. Mais recentemente, no século XX, o modelo de ocupação e incorporação do território nas regiões Norte e Centro-Oeste originou redes urbanas 
com pouca densidade, de forma que na centralidade em saúde, em nível 4, aparecem oito cidades na região Norte e apenas uma na Centro-Oeste, que são: Porto Velho (RO), Rio Branco (AC), Boa Vista (RR), Ananindeua e Santarém (PA), Macapá (AP), Araguaína e Palmas (TO) e Anápolis (GO).

O Quadro 4 dá uma ideia de como os níveis de centralidade 5 e 6 e o 0 (sem centralidade) retratam uma estrutura em saúde com lacunas nos escalões urbanos mais baixos que, em certa medida, reproduzem o sistema urbano brasileiro. Se o nível 4 de centralidade for considerado um escalão intermediário no atendimento a serviços de saúde, pode-se afirmar que são numericamente poucos em um país com as dimensões do Brasil e com distribuição desigual no território. Os níveis 5 e 6, de menor complexidade, por exemplo, são formados por diversas classes de complexidade, de 1 até 0 , demonstrando desequilíbrios agudos na distribuição de serviços de saúde e com combinações com as classes de volume que classificam grande parte dos centros urbanos no nível 6.

São 342 centros classificados na $5^{\mathrm{a}}$ classe de centralidade em saúde, com condições de atender casos de complexidade de média para baixa. Do total de centros nesta classe, 223 são polos de regiões imediatas e, neste escalão, a presença de eletrocardiógrafo, entre outros instrumentos, e de especializações com patamar de complexidade em obstetrícia, análises clínicas, pediatria, ginecologia e clínica médica classificam os centros.

Os equipamentos e especialidades mais frequentes estão disponíveis nos centros urbanos com centralidade 6, que são centros de menor porte e complexidade baixa e estão presentes em quase todo o território nacional, totalizando 3.997 centros em que parte significativa não possui internações ou esse valor não ultrapassa o patamar de 0,01\% das internações. No nível de centralidade 6 ocorre, também, a desigualdade na distribuição geográfica do fornecimento de serviços de saúde, uma vez que as regiões Nordeste, Sudeste e Sul contabilizam inúmeros centros neste patamar, enquanto nas regiões Norte e Centro-Oeste eles representam 14,0\% no total, são reduzidos e classificam inúmeros polos de regiões imediatas.

Cabe mencionar que 1.132 centros não possuem centralidade, uma vez que não registraram a presença de equipamentos e especialidades, assim como internações hospitalares. A lógica da oferta de bens e serviços é que a população de municípios com baixa centralidade ou sem centralidade se desloque para municípios com mais alta centralidade quando necessitam de serviços de maior complexidade.

Tal esquema, de busca por centros de hierarquia superior para atendimento em procedimentos de mais alta complexidade, parece razoável quando o sistema urbano se configura mais bem distribuído hierarquicamente na sua geografia. Entretanto, no caso brasileiro, redunda em atendimento desequilibrado, com concentração em poucos centros nos níveis de alta centralidade, que exercem forte polarização em suas áreas, enquanto outras áreas são precárias no atendimento a serviços em saúde.

À guisa de exemplo, pode-se citar a presença de numerosos centros com centralidade 6 e sem centralidade localizados em ACPs de São Paulo (SP), Recife (PE), Belo Horizonte (MG), Porto Alegre (RS), Rio de Janeiro (RJ), entre outras, que reúnem, em cada uma, inúmeros municípios. Quanto à precariedade nos serviços, Oliveira, Carvalho e Travassos afirmam que nas redes de alta 
complexidade, onde poucos centros têm capacidade de atendimento hospitalar, o atendimento é limitado pela disponibilidade e capacidade das pessoas para deslocar-se: "apenas $3 \%$ dos pacientes internados para cirurgia cardíaca residiam em municípios situados a mais de $60 \mathrm{~km}$ do centro em que se internaram e nestes municípios concentram-se cerca de 40,0\% da população brasileira" (Oliveira, Carvalho \& Travassos, 2004: 399).

A Figura 8 sintetiza a distribuição dos centros, segundo as classes de centralidade, variando do $1^{\circ}$ nível ao $6^{\circ}$ e a hierarquia urbana até os centros de zona (IBGE, 2008). Observa-se que as regiões imediatas de articulação urbana apresentam, cada uma delas, um polo de maior hierarquia que comanda e articula a sua região e um ou mais centros subordinados a esse polo, dando origem a formas espaciais organizadas segundo redes de atendimento imediato no setor Saúde.

As regiões imediatas, que recortam a Figura 8, têm ligações que refletem a acessibilidade e a capacidade de atender demandas de amplitude espacial mais restritas, em redes comandadas por centros desde metrópoles até os de menor hierarquia, como os centros de zona e em todos os níveis de centralidade em saúde. A rede urbana, com nós que apoiam as diversas atividades, gera fluxos variados mediante as novas tecnologias. Essa arquitetura permite identificar a funcionalidade dos centros e a complementaridade entre eles e, consequentemente, as vantagens locacionais que imprimem a diferenciação a partir do nível mais alto da hierarquia para os centros dispostos nos níveis inferiores e, nesse contexto, estabelecer intervenções para aprimorar a rede de saúde.

Quanto à dinâmica populacional, a Figura 9 desenha, para 2033, três grandes tendências no comportamento populacional, mantendo-se, sobretudo, as condições atuais no que tange aos aspectos econômicos, sociais e ambientais: as áreas de estabilidade, as de maior atração e as com perda populacional. As áreas de estabilidade estarão presentes em grande parte do território nacional e ocuparão quase toda a porção leste do país. Trata-se da parte mais densamente povoada, cuja estabilidade se amplia, uma vez que o ritmo de crescimento populacional tende a diminuir em decorrência do comportamento das taxas vitais. O novo cenário indica também a presença de uma faixa de estabilidade que divide as áreas de atração populacional e se estende do Pará até o Mato Grosso do Sul.

As áreas de atração ocupam grande parte das regiões Norte e Centro-Oeste, ocorrem nas grandes aglomerações urbanas e no litoral e mantêm um eixo de crescimento nas divisas entre as regiões Centro-Oeste e Sudeste, ao longo da rodovia Belém-Brasília, avançando em áreas da Bahia, Maranhão e Piauí.

De maneira geral são áreas com centralidade baixa em saúde e situação frágil quanto aos leitos por habitantes. Em sua maioria consistem em regiões imediatas e centros em menor número, ocupando grandes áreas, e também em regiões com os polos classificados nos níveis mais baixos de centralidade em saúde. Roraima, com apenas uma região imediata de articulação urbano-regional, possui uma rede com 15 centros urbanos, sete deles sem centralidade e sete com centralidade de baixa complexidade, destinando a Boa Vista - com centralidade 4 ou a Manaus com centralidade 2 - o atendimento em procedimentos de média e alta complexidade. Outra unidade federada com as mesmas características é o Amapá. 
As regiões imediatas litorâneas e as que abrigam a maioria dos grandes centros urbanos continuarão a atrair população, reforçando a necessidade de aumento de serviços para o atendimento nessas redes de mais alta complexidade. As grandes metrópoles do país, assim como outros centros com centralidade alta em saúde, provavelmente se manterão como os principais polos para os serviços de saúde. Este padrão de atendimento demonstra ser extremamente seletivo e desigual, uma vez que nem todos podem realizar deslocamentos para tratamento, principalmente aqueles de longa distância.

Quanto às regiões imediatas que mostram tendência de perda populacional, pode-se adiantar que estão localizadas, em maior número, na região Sul, que tradicionalmente apresenta um quadro demográfico com taxas negativas de crescimento. Nessas áreas o envelhecimento populacional, combinado com a emigração de força de trabalho jovem e adulta, contribui para a redução do volume demográfico. As regiões classificadas nesses padrões demográficos possuem quase todos os centros com centralidade em saúde entre 5 e 6, com atendimento de baixa complexidade, exceto Ilhéus-Itabuna (BA), classificada em nível 4.

Para finalizar, cabe reforçar a principal característica da população brasileira, que é a de cada vez mais concentrar-se em centros urbanos. Mais de $84 \%$ da população vivem em situação urbana, e este é um dos processos mais importantes da contemporaneidade, pois reúne ao longo de décadas, em espaços relativamente restritos, população e atividades. Do ponto de vista territorial, produz arranjos populacionais cujas características impulsionam processos socioespaciais bastante diferenciados quanto à densidade, fragmentação, orientação e centralidade. No Brasil, crescimento econômico e desenvolvimento urbano, consequentemente com acesso a melhores serviços e qualidade de vida, nem sempre caminham lado a lado, o que implica a necessidade de o Estado intervir e atuar para proteger os menos favorecidos.

Os estudos mais recentes, como Regiões de Influência das Cidades - 2007 (IBGE, 2008), que consideram, em seu escopo teórico-metodológico, a capacidade de concentração econômica e a infraestrutura, mostram, conforme já se afirmou, uma forte polarização de poucos centros, principalmente nas regiões Sudeste e Sul, formando redes urbanas onde a localização revela-se mais importante que o tamanho ou a posição na rede urbana.

Em contrapartida, se o modelo de crescimento tem sido feito por meio da expansão do mercado interno e do reforço das desigualdades, as políticas socioeconômicas devem atuar a fim de diminuir as lacunas em setores fundamentais como a saúde e a educação. Os programas implementados têm alcançado a população mais pobre, de forma a diminuir as disparidades de acesso aos serviços básicos, mas a persistência de crises constantes nestes setores revela-se preocupante.

Para um cenário futuro, as políticas de saúde devem respeitar as relações complexas entre economia e território, pois configuram um desafio num contexto de disparidades e diversidade do espaço nacional. 
Figura 8 - Características de atendimento à saúde e hierarquia urbana - 2010-2033

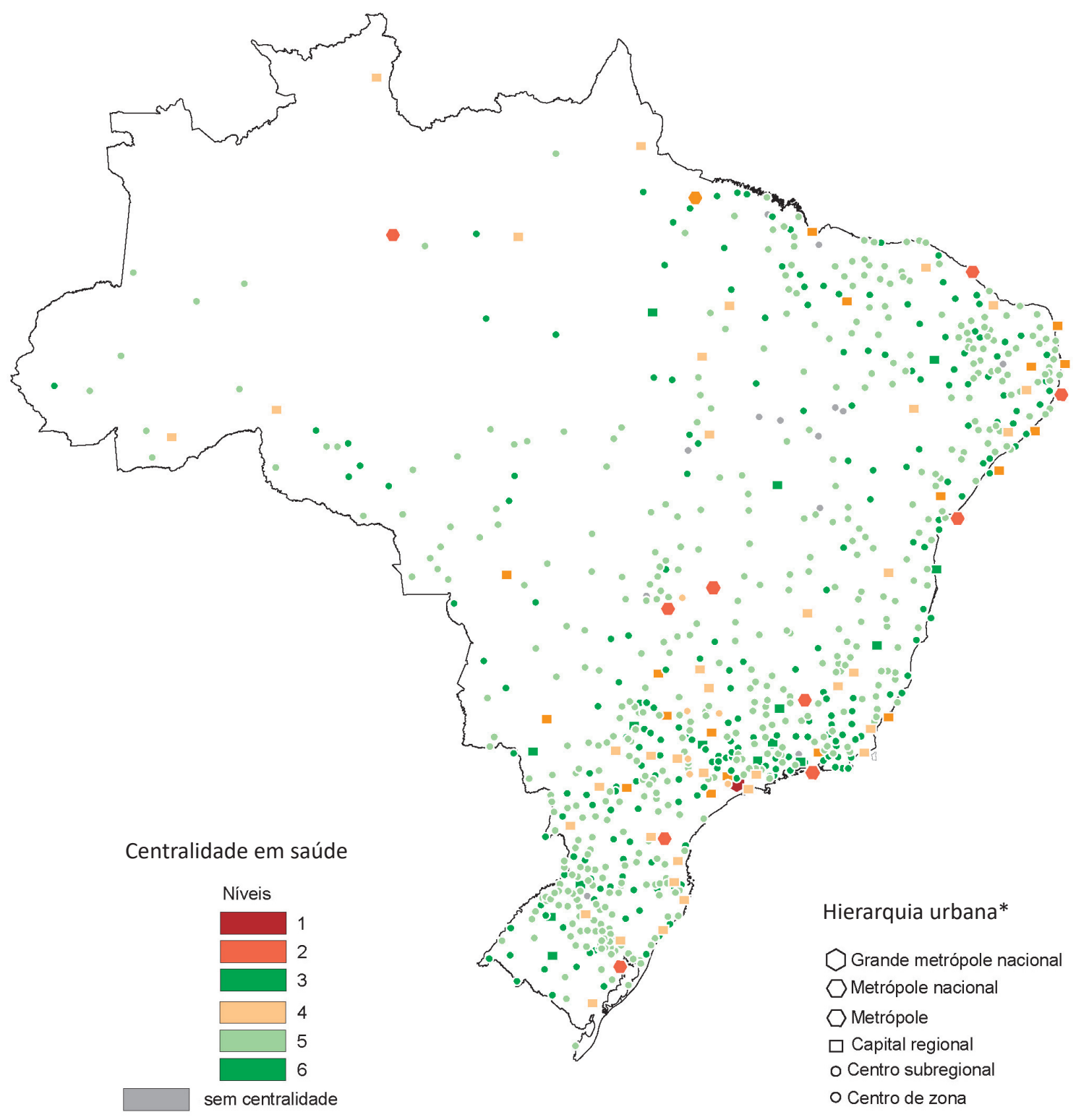

* Dados organizados por regiões imediatas de articulação urbana e centros urbanos até o nível de centros de zona. Fonte: elaboração dos autores com base em IBGE, 2008, 2010. 
Figura 9 - Tendências da dinâmica populacional - 2010-2033*

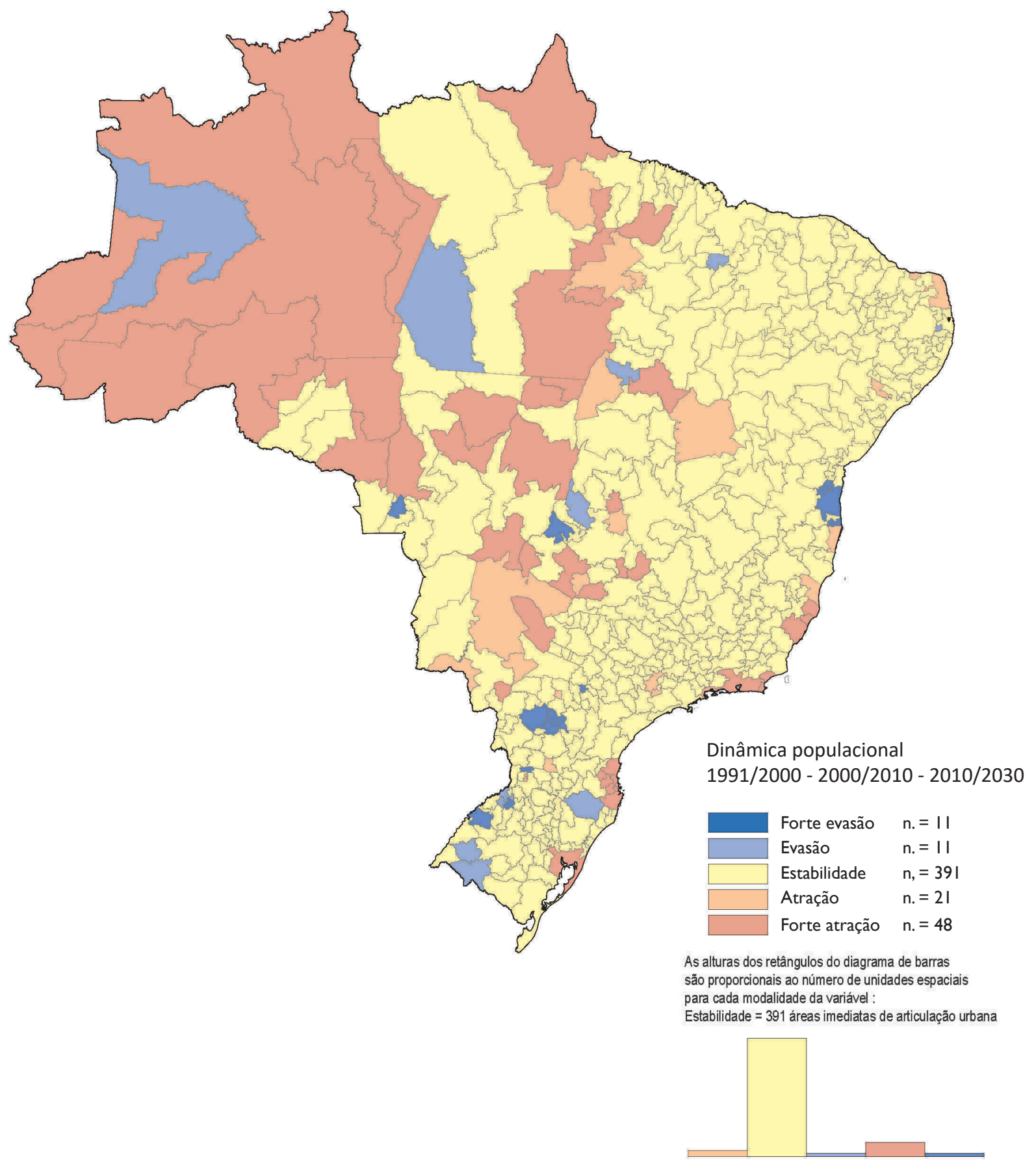

* Dados organizados por regiões imediatas de articulação urbana e centros urbanos até o nível de centros de zona. Os centros urbanos que formam ACPs, com exceção do núcleo, não foram mapeados.

Fonte: elaboração dos autores com base nos Censos Demográficos de 1991, 2000 e 2010 (IBGE, 2014a, 2014b, 2014c). 


\section{Considerações Finais}

Destacam-se, neste capítulo, as profundas assimetrias na dinâmica demográfica e na oferta dos serviços de saúde entre diversas regiões do país. Tais diferenças e desigualdades respondem aos distintos estágios de desenvolvimento econômico e social dessas áreas. Como visto, o ritmo de declínio das taxas de fecundidade total tende a pressionar este indicador que ficará em um nível abaixo da reposição em todo o território nacional; o processo de envelhecimento populacional segue tendência crescente e inexorável; e a chamada “janela demográfica”, que está se fechando no Sudeste e Sul, ainda permanecerá aberta por um período maior de tempo no Norte e Nordeste. A transição demográfica brasileira tem como caraterística marcante ao menos duas transições dentro dela, ao norte e ao sul do país. Esse cenário, que produzirá impactos importantes no mercado de trabalho, na produtividade da força de trabalho, no sistema de proteção e previdência social e na área da saúde, deve ser levado em consideração no momento de definição das políticas públicas.

Os desafios são enormes. O aproveitamento do que resta do bônus demográfico, o desejado salto tecnológico e o necessário aumento da produtividade, para fazer frente contra um quadro futuro de redução da população em idade de trabalhar, requerem investimento na melhoria da qualidade do ensino. Isto significa pensar educação e mercado de trabalho na perspectiva do envelhecimento da população.

Do ponto de vista da proteção social, embora os impactos do envelhecimento na previdência social sejam os mais propalados, gerando um certo catastrofismo por parte dos setores mais conservadores da sociedade, devem ser pensadas as questões que dizem respeito aos cuidados e atenção integral à população idosa, o que demandará infraestrutura de serviços que garantam vida ativa e integrada socialmente, sem perder de vista a necessidade da atenção às crianças e aos adolescentes.

Em relação à saúde, normalmente são feitas referências aos tipos de morbidades correlacionadas ao aumento da população em idades avançadas, que demandarão pesados investimentos. Contudo, pouco se fala do crescimento do segmento adulto jovem que aumentará o volume de pessoas expostas às morbidades e óbitos associados às causas externas. Esse aspecto da transição demográfica introduz uma questão até então não colocada na agenda da saúde.

Ressaltamos que não se pode desconsiderar as disparidades regionais na dinâmica demográfica e na oferta dos serviços de saúde. O cenário para os próximos vinte anos sinaliza estabilidade no crescimento populacional na maior parte das regiões imediatas de articulação. Poucas regiões continuarão a atrair população e algumas outras poucas seguirão como áreas de evasão populacional, o que poderá proporcionar maior segurança num planejamento que combine a tendência demográfica e os níveis de centralidade em saúde.

Enfim, todas essas políticas devem ser pensadas no âmbito de projeto de nação que vise a alcançar o desenvolvimento econômico e social a ser aproveitado por toda a sociedade. Isso implica eliminar ou reduzir drasticamente as desigualdades, pautar-se pela garantia dos direitos humanos e investir na prestação de serviços que sejam universais. 


\section{Referências}

CASTELO BRANCO, CASTELO BRANCO, M. L. G. Áreas de concentração de população. In: ENCONTRO NACIONAL DE PRODUTORES E USUÁRIOS DE INFORMAÇÕES SOCIAIS, ECONÔMICAS E TERRITORIAIS, 2, 2006, Rio de Janeiro. Anais.... Rio de Janeiro: IBGE, 2006.

BRASIL. Ministério do Trabalho e Previdência Social. Site. Disponível em: <http://portal.mte.gov.br/data/fi les/8A7C816A2E7311D1012ED8D282D817AF/1\%20-\%20Autoriza\%C3\%A7\%C3\%B5es\%20Concedidas\%20 a\%20Estrangeiros\%20por\%20Tipo\%20de\%20visto.pdf>. Acesso em: 6 jan. 2014.

CANALES, A. I. Discurso demográfico y posmodernidad: una revisión crítica del pensamiento malthusiano. Estudios Sociológicos, 19(2): 381-417, 2001.

CARVALHO, J. A. M. O saldo dos fluxos migratórios internacionais no Brasil na década de 80: uma tentativa de estimação. In: PATARRA, N. L. (Org.). Emigração e Imigração Internacionais no Brasil Contemporâneo. Campinas, São Paulo: Fnuap, Oficina Editorial, 1996.

INSTITUTO BRASILEIRO DE GEOGRAFIA E ESTATÍSTICA (IBGE). Regiões de Influência das Cidades 2007. Rio de Janeiro: IBGE, 2008.

INSTITUTO BRASILEIRO DE GEOGRAFIA E ESTATÍSTICA (IBGE). Pesquisa de Assistência Médico-Sanitária 2009. Rio de Janeiro: IBGE, 2010.

INSTITUTO BRASILEIRO DE GEOGRAFIA E ESTATÍSTICA (IBGE). Divisão Urbano-Regional do Brasil 2013. Rio de Janeiro: IBGE, 2013a.

INSTITUTO BRASILEIRO DE GEOGRAFIA E ESTATÍSTICA (IBGE). Projeção da população do Brasil por sexo e idade para o período 2000/2060. Projeção da população das Unidades da Federação por sexo e idade para o período 2000/2030. Rio de Janeiro: IBGE, 2013b. Disponível em: <ftp://ftp.ibge.gov.br/Projecao_da_Populacao/ Projecao_da_Populacao_2013/nota_metodologica_2013.pdf>. Acesso em: 5 jan. 2014.

INSTITUTO BRASILEIRO DE GEOGRAFIA E ESTATÍSTICA (IBGE). Censo Demográfico de 1991. Rio de Janeiro: IBGE. Disponível em: <www.ibge.gov.br/home/estatistica/populacao/censodem/default.shtm>. Acesso em: 5 jan. 2014a.

INSTITUTO BRASILEIRO DE GEOGRAFIA E ESTATÍSTICA (IBGE). Censo Demográfico de 2000. Rio de Janeiro: IBGE. Disponível em: <www.ibge.gov.br/home/estatistica/populacao/censo2000/default.shtm>. Acesso em: 5 jan. 2014b.

INSTITUTO BRASILEIRO DE GEOGRAFIA E ESTATÍSTICA (IBGE). Censo Demográfico de 2010. Rio de Janeiro: IBGE. Disponível em: <www.ibge.gov.br/home/estatistica/populacao/censo2010/caracteristicas_da_populacao/ default_caracteristicas_da_populacao.shtm >. Acesso em: 5 jan. 2014c.

OLIVEIRA, A. T. R. \& O’NEILL, M. M. V. C. Cenário sociodemográfico em 2022/2030 e distribuição territorial da população: uso e ocupação do solo. In: GADELHA, P.; CARVALHO, J. N. \& PEREIRA, T. R. (Orgs.). A Saúde do Brasil em 2030: diretrizes para a prospecção estratégica do sistema de saúde brasileiro. v. 1. Rio de Janeiro: Editora Fiocruz, Ipea, Ministério da Saúde, Secretaria de Assuntos Estratégicos da Presidência da República, 2013.

OLIVEIRA, A. T. R. et al. Notas sobre a migração internacional no Brasil na década de 80. In: PATARRA, N. L. (Coord.). Emigração e Imigração Internacionais no Brasil Contemporâneo. Campinas, São Paulo: Fnuap, Oficina Editorial, 1996.

OLIVEIRA, E. X. G.; CARVALHO, M. S. \& TRAVASSOS, C. Territórios do Sistema Único de Saúde: mapeamento das redes de atenção hospitalar. Cadernos de Saúde Pública, 20(2): 386-402, 2004.

PEREIMA, J. B. \& PORSSE, A. A transição demográfica, acumulação de capital e progresso tecnológico: desafios para o crescimento brasileiro. Revista Economia \& Tecnologia, 9(1): 49-60, 2013.

SIMÕES, C. C. S. A Transição da Fecundidade no Brasil: análise de seus determinantes e as novas questões demográficas. São Paulo: Arbeit Factor, 2006. 